\title{
The Aromatase Gene CYP19A1: Several Genetic and Functional Lines of Evidence Supporting a Role in Reading, Speech and Language
}

\author{
Heidi Anthoni - Lara E. Sucheston - Barbara A. Lewis - Isabel Tapia-Páez • \\ Xiaotang Fan · Marco Zucchelli • Mikko Taipale • Catherine M. Stein • \\ Marie-Estelle Hokkanen • Eero Castrén • Bruce F. Pennington - Shelley D. Smith • \\ Richard K. Olson • J. Bruce Tomblin • Gerd Schulte-Körne • Markus Nöthen • \\ Johannes Schumacher • Bertram Müller-Myhsok • Per Hoffmann • \\ Jeffrey W. Gilger • George W. Hynd • Jaana Nopola-Hemmi • Paavo H. T. Leppanen • \\ Heikki Lyytinen · Jacqueline Schoumans • Magnus Nordenskjöld • \\ Jason Spencer • Davor Stanic • Wah Chin Boon • Evan Simpson • \\ Sari Mäkelä · Jan-Åke Gustafsson • Myriam Peyrard-Janvid • Sudha Iyengar • \\ Juha Kere
}

Received: 22 August 2011/Accepted: 11 February 2012/Published online: 17 March 2012

(C) The Author(s) 2012. This article is published with open access at Springerlink.com

\begin{abstract}
Inspired by the localization, on $15 \mathrm{q} 21.2$ of the CYP19A1 gene in the linkage region of speech and language disorders, and a rare translocation in a dyslexic individual that was brought to our attention, we conducted a series of studies on the properties of CYP19A1 as a candidate gene for dyslexia and related conditions. The aromatase enzyme is a member of the cytochrome P450
\end{abstract}

Edited by Valerie Knopik.

Electronic supplementary material The online version of this article (doi:10.1007/s10519-012-9532-3) contains supplementary material, which is available to authorized users.

\section{H. Anthoni · J. Kere}

Department of Medical Genetics, Biomedicum,

University of Helsinki, 00014 Helsinki, Finland

H. Anthoni - M.-E. Hokkanen · E. Castrén

Neuroscience Center, University of Helsinki, 00014 Helsinki,

Finland

\section{E. Sucheston}

Department of Biostatistics, State University of New York at Buffalo, Buffalo, NY 14214-3000, USA

B. A. Lewis

Department of Psychological Sciences, Case Western Reserve University, Cleveland, OH 44106, USA

I. Tapia-Páez · X. Fan · M. Zucchelli · J.-A. Gustafsson · M. Peyrard-Janvid $(\bowtie) \cdot$ J. Kere

Department of Biosciences and Nutrition, Karolinska Institutet,

14183 Huddinge, Sweden

e-mail: Myriam.Peyrard@ki.se super family, and it serves several key functions: it catalyzes the conversion of androgens into estrogens; during early mammalian development it controls the differentiation of specific brain areas (e.g. local estrogen synthesis in the hippocampus regulates synaptic plasticity and axonal growth); it is involved in sexual differentiation of the brain; and in songbirds and teleost fishes, it regulates vocalization. Our results suggest that variations in CYP19A1 are associated with dyslexia as a categorical trait and with quantitative measures of language and speech, such as reading, vocabulary, phonological processing and oral

M. Taipale

Whitehead Institute for Biomedical Research, Nine Cambridge

Center, Cambridge, MA 02142-1479, USA

C. M. Stein $\cdot$ S. Iyengar

Department of Epidemiology and Biostatistics, Case Western

Reserve University, Cleveland, OH 44106, USA

B. F. Pennington

Department of Psychology, University of Denver,

Denver, CO 80208, USA

S. D. Smith

Munroe Meyer Institute, University of Nebraska Medical Center, Omaha, NE 68198-5450, USA

R. K. Olson

Department of Psychology, University of Colorado,

Boulder, CO, USA 
motor skills. Variations near the vicinity of its brain promoter region altered transcription factor binding, suggesting a regulatory role in CYP19A1 expression. CYP19A1 expression in human brain correlated with the expression of dyslexia susceptibility genes such as $D Y X 1 C 1$ and $R O B O 1$. Aromatasedeficient mice displayed increased cortical neuronal density and occasional cortical heterotopias, also observed in Robo1-/- mice and human dyslexic brains, respectively. An aromatase inhibitor reduced dendritic growth in cultured rat neurons. From this broad set of evidence, we propose CYP19A1 as a candidate gene for human cognitive functions implicated in reading, speech and language.

Keywords Dyslexia - SSD - SLI - Estrogen synthesis · Translocation breakpoint - Quantitative trait analysis . Categorical trait association

\section{Introduction}

Online Mendelian inheritance in man (OMIM, www.ncbi. nlm.nih.gov/omim) documents nine loci in the human genome, $D Y X 1-9$, for developmental dyslexia or specific reading disability, the most common learning disorder (Scerri and Schulte-Korne 2010). Those loci and their associated genes are: DYX1 on 15q21 (DYX1C1), DYX2 on 6p22.2 (DCDC2 and KIAA0319), DYX3 on 2p16-p11 (MRPL19 and C2orf3), DYX4 on 6q11.2-q12, DYX5 on 3p12-q13 (ROBO1), DYX6 on 18p11.2, DYX7 on 11p15.5, $D Y X 8$ on 1p36-34 and DYX9 on Xq27.3. Other regions and

\author{
J. B. Tomblin \\ Department of Communication Sciences and Disorders, \\ University of Iowa, Iowa City, IA 52242, USA \\ G. Schulte-Körne \\ Department of Child and Adolescent Psychiatry, Psychosomatics \\ and Psychotherapy, Ludwig-Maximilians-University of Munich, \\ 80336 Munich, Germany \\ M. Nöthen · P. Hoffmann \\ Department of Genomics, Life and Brain Centre, \\ University of Bonn, 53127 Bonn, Germany \\ M. Nöthen · J. Schumacher · P. Hoffmann \\ Institute of Human Genetics, Biomedical Centre, \\ University of Bonn, 53127 Bonn, Germany \\ B. Müller-Myhsok \\ Max-Planck Institute of Psychiatry, 80804 Munich, Germany \\ J. W. Gilger \\ Psychological Sciences, University of California, Merced, \\ CA 95343, USA \\ G. W. Hynd \\ Department of Psychology, College of Charleston, \\ 66 George Street, Charleston, SC 29424, USA
}

genes have also recently emerged as dyslexia candidate genes (Poelmans et al. 2009; Matsson et al. 2011).

Two different chromosomal translocations associated with developmental dyslexia have been reported in two Finnish families (Nopola-Hemmi et al. 2000). In the first family, the breakpoint was localized to $15 \mathrm{q} 21$ interrupting the $D Y X 1 C 1$ gene at the $D Y X 1$ locus (Taipale et al. 2003). $D Y X 1 C 1$ is considered a strong dyslexia susceptibility gene and has been shown to play a role in neuronal migration, auditory processing and learning (Wang et al. 2006; Rosen et al. 2007; Threlkeld et al. 2007; Poelmans et al. 2010). Association studies of DYX1C1 to dyslexia have been controversial; efforts to replicate the originally associated SNPs produced conflicting results suggesting that there might be another gene responsible for dyslexia in this region (Schumacher et al. 2007; Scerri and Schulte-Korne 2010). The second chromosomal translocation $\mathrm{t}(2 ; 15)$ (p12;q21) segregated in a Finnish family and co-occurred in one individual with phonological awareness problems leading to severe dyslexia. The translocation maps 6-8 Mb centromeric from DYX1C1 (Nopola-Hemmi et al. 2000), suggesting that $D Y X 1$ might harbor another gene for dyslexia. In addition, the $15 \mathrm{q}$ region has also been implicated in speech and language development, specifically in speech-sound disorder (SSD), a human developmental disorder characterized by deficits in articulation and in cognitive representation of speech sounds or phonemes (Stein et al. 2006; Smith 2007; Chen et al. 2008). Also supporting a shared biology between SSD and dyslexia, is that other SSD loci co-localize with dyslexia loci, such as

J. Nopola-Hemmi

Division of Child Neurology, Department of Gynecology and Pediatrics, HUCH, University of Helsinki, 00014 Helsinki,

Finland

P. H. T. Leppanen - H. Lyytinen

Department of Psychology, University of Jyväskylä, 40014 Jyväskylä, Finland

J. Schoumans · M. Nordenskjöld

Department of Molecular Medicine and Surgery,

Karolinska Institutet at Karolinska University Hospital,

17176 Stockholm, Sweden

J. Spencer - D. Stanic · W. C. Boon

Howard Florey Institute, Parkville, VIC 3010, Australia

J. Spencer · W. C. Boon

Department of Anatomy and Developmental Biology,

Monash University, Clayton, VIC 3800, Australia

D. Stanic - W. C. Boon

Centre for Neuroscience, University of Melbourne,

Parkville, VIC 3010, Australia 
$D Y X 5$ that includes the axon guidance gene, $R O B O 1$ (Hannula-Jouppi et al. 2005).

Early receptive and expressive language skills in early childhood have been shown to predict the later reading skills and to be linked to emergence of dyslexia in families at high risk (Torppa et al. 2010). Developmental spoken language problems are also associated with reading difficulties, for example, about $25-50 \%$ of SSD probands develop dyslexia (Raitano et al. 2004; Stein et al. 2006). Further, brain responses to auditory stimuli measured at birth, have been shown to differ between children with a familial background of dyslexia who developed dyslexia at school age, in comparison to typical readers without any familial background of dyslexia (Leppanen et al. 2010). These newborn brain responses were also associated with phonological skills before school entry and speech perception at school age. There is also evidence that specific language impairment (SLI) and dyslexia share common etiological factors that at least partly are genetically influenced (Catts et al. 2005; Newbury et al. 2011). Children with SLI have normal nonverbal intelligence but have persistent poor development in some or all of the areas of receptive and expressive grammar, phonology and vocabulary; in addition reading disorder is common among SLI children (Shriberg et al. 1999; Catts et al. 2002; Bishop and Snowling 2004). It is possible that the common etiologic link among dyslexia, SLI and SSD is in the domain of phonological processing and phonological memory (Dollaghan and Campbell 1998; Conti-Ramsden and Hesketh 2003; Pennington 2006), although each condition is recognized as a distinct developmental disorder of speech or language with its own unique characteristics as well (Catts et al. 2005; Smith 2007).

In this study, we mapped the previously uncharacterized breakpoint of the second translocation $\mathrm{t}(2 ; 15)(\mathrm{p} 12 ; \mathrm{q} 21)$ we saw in our clinic and showed that it disrupts an area at $15 \mathrm{q} 21.2$, the complex promoter region of the aromatase gene, CYP19A1. Aromatase, or estrogen synthase, is a

W. C. Boon - E. Simpson

Prince Henry's Institute of Medical Research, Clayton, VIC 3168, Australia

\section{S. Mäkelä}

Institute of Biomedicine, University of Turku,

20014 Turku, Finland

\section{J.-Å. Gustafsson}

Center for Nuclear Receptors and Cell Signaling,

University of Houston, Houston, TX 77204-5056, USA

\section{J. Kere}

Department of Clinical Research Center, Karolinska Institutet, 14183 Huddinge, Sweden

J. Kere

Science for Life Laboratory, Karolinska Institutet,

17165 Solna, Sweden cytochrome P450 super family enzyme that converts C19 androgens, such as androstenedione and testosterone, into C18 estrogens, estrone and estradiol-17 $\beta$, respectively. Aromatase is important in sexual differentiation and is expressed in the gonads of both sexes but also in a variety of other tissues such as the central nervous system, contributing to a local synthesis of estrogens outside of the reproductive system (Boon et al. 2010; Azcoitia et al. 2011). In the embryonic and early postnatal mammalian brain, aromatase is responsible for sexual differentiation of specific brain areas (Naftolin et al. 2001). Aromatase is also found expressed in radial glial cells of the mouse embryonic neocortex, a cell population that generates neurons during embryogenesis (Martinez-Cerdeno et al. 2006) as well as in adult radial glial cells in zebrafish, progenitor cells of the developing and adult fish brains (Diotel et al. 2010). Estrogens have important roles in brain development and neuronal differentiation by influencing cell migration, survival and death (Beyer 1999; GarciaSegura 2008). They also have an important role in learning and memory by increasing the density of dendritic spines in hippocampal pyramidal cells and enhancing excitability and synaptic plasticity (Hao et al. 2006; Prange-Kiel and Rune 2006). Interestingly, Cyp19al has an important role in the control of vocalization and behavior in songbirds and teleost fish (Forlano et al. 2006; Diotel et al. 2010).

We hypothesized that the CYP19A1 gene, shown to be disrupted by the translocation $\mathrm{t}(2 ; 15)(\mathrm{p} 12 ; \mathrm{q} 21)$, influences speech and language early in life, and reading at school age. Therefore, we tested the gene for association with a diagnosis of dyslexia and language-related quantitative traits (QTs) in six different samples from Finland, Germany and the USA. We also characterized several functional properties of the CYP19A1 gene and its products, such as the correlation of its mRNA expression with other dyslexiaassociated genes, in different regions of adult human brain; the binding capacity of specific transcription factors to two SNPs surrounding the brain specific promoter of the gene; and in vivo studies of the aromatase role in the growth of rat embryonic hippocampal neurons as well as in the formation of the cortex in mice. Taken together, our findings provide a broad evidence base for the role of aromatase in brain development relevant to reading, speech and language.

\section{Results}

The translocation breakpoint $\mathrm{t}(2 ; 15)(\mathrm{p} 12 ; \mathrm{q} 21)$, in a dyslexic individual, disrupts the complex promoter region of the CYP19A1 gene on $15 \mathrm{q} 21.2$

Using fluorescence in situ hybridization (FISH) and Southern blot analysis, we refined both translocation 


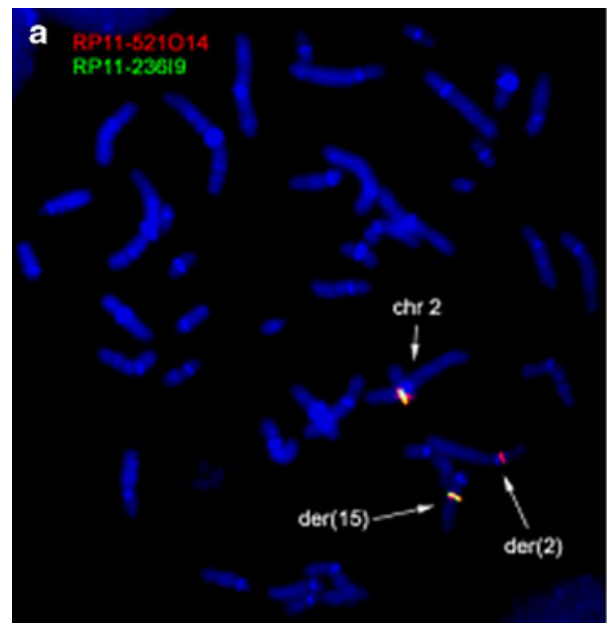

Fig. 1 FISH detecting the $t(2 ; 15)(\mathrm{p} 12 ; \mathrm{q} 21)$ with chromosome 2- and 15 -specific BAC probes, on metaphases from a dyslexic individual. a Chromosome 2 probe, BAC clone RP11-521014, shows hybridization signals on chromosomes $2, \operatorname{der}(2)$, and $\operatorname{der}(15)$ (red). Probe

breakpoints in the individual with $\mathrm{t}(2 ; 15)(\mathrm{p} 12 ; \mathrm{q} 21)$ and dyslexia (Nopola-Hemmi et al. 2000). The chromosome 2 breakpoint mapped to an unremarkable region on $2 \mathrm{q} 12$, recognized by the bacterial artificial chromosome (BAC) RP11-521O14 and distinct from the DYX3 locus (Fig. 1a). This $200 \mathrm{~kb}$ region on $2 \mathrm{p} 12$ is very repeat-rich and contains no known genes. Furthermore, no new genes could be identified from this region by gene prediction programs and PCR on a panel of human cDNA libraries. The gene desert stretches $\sim 2 \mathrm{Mb}$ on both sides on the breakpoint, which is $\sim 6.5 \mathrm{Mb}$ centromeric and therefore distinct from our previously reported DYX3 locus (Anthoni et al. 2007).

The chromosome 15 breakpoint mapped to $15 \mathrm{q} 21.2$, recognized by BAC clone RP11-108K3 (Fig. 1b), and further Southern blot analysis (data not shown) identified the exact breakpoint to the regulatory region of CYP19A1 and more specifically, to the region between the promoter for skin, adipose tissue and fetal liver (I.4) and the promoter for fetal tissue (I.5), $\sim 22 \mathrm{~kb}$ upstream from the brain-specific exon/promoter I.f (Fig. 2b).

SNPs within CYP19A1 are associated with the dyslexia categorical trait and with phonological phenotypes

Six cohorts of family-based material of Caucasian origin (Table 1) were genotyped for 16-20 SNPs located in the CYP19A1 gene.

\section{Moderate association to dyslexia as a categorical trait}

To test for association with dyslexia in the Finnish (FI, DYS), the German (GER, DYS) and the Georgia (GA, US,

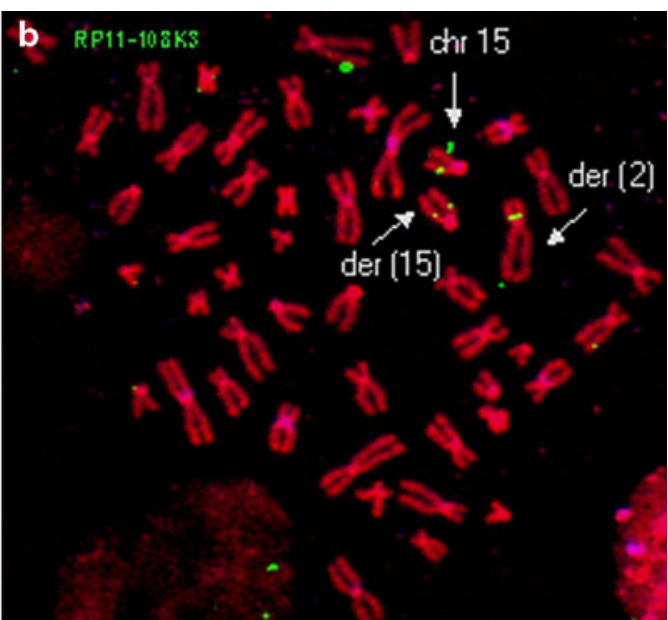

RP11-23619, distal to the breakpoint, hybridizes only to chromosome 2 and $\operatorname{der}(15)$ (green). b Chromosome 15 probe, BAC clone RP11$108 \mathrm{~K} 3$, shows hybridization signals on chromosomes 15 , der(15), and der(2) (green)

DYS) dyslexia cohorts, as well as the SSD cohort (OH, US, SSD), pedigree disequilibrium test (PDTPHASE) was used in order to maximize power in these family and trio materials. In the GER, DYS dataset, no haplotype was significantly associated to the dyslexia phenotype (data not shown). In the FIN, DYS dataset, there was evidence of transmission distortion to dyslexia-affected offspring for one haplotype, rs8034835-rs2899472 (GC, $p=0.039$ ) (Fig. 2d), stretching from intron 4 to intron 5 of the gene (Fig. 2b, c). This haplotype overlaps with one of the significant haplotypes (rs8034835-rs2899472-rs1065778-rs70 0518, GCAG, $p=0.032$ ) in the SSD cohort when tested for association to the dyslexia trait, as $\sim 45 \%$ of the affected individuals from this cohort are dyslexic. The other significant haplotype in the SSD cohort, rs1902586rs936306-rs2470176-rs2470152 (GCAG, $p=0.023$; Fig. 2d), is located more upstream of the gene, between the translocation breakpoint and the brain specific exon/promoter I.f (Fig. 2b, c). Interestingly, in the Georgia dyslexia cohort (GA, US, DYS), the only significant haplotype, rs11632903-rs1902586 (TG, $p=0.023$; Fig. $2 \mathrm{~d}$ ) overlaps with the significant haplotype rs1902586-rs936306-rs2470176-rs2470152 (GCAG) of the $\mathrm{OH}$, SSD cohort (Fig. 2d). PDT is used only for family data and therefore could not be applied to the Colorado dyslexia (CO, US, DYS) and the SLI (IA, US, SLI) cohorts, as we lacked dyslexia status for the parents of each proband. In summary, three of the four cohorts where family material was available, do show a moderate ( $p$-values significant at the 0.05 level) association between dyslexia, as a categorical trait, and a number of SNP/haplotypes from the CYP19A1 gene. The most significant haplotype in each of the Finnish and Georgian dyslexia cohorts is fully or partially overlapping with one of the two significant haplotypes from the SSD cohort (Fig. 2d), 
a
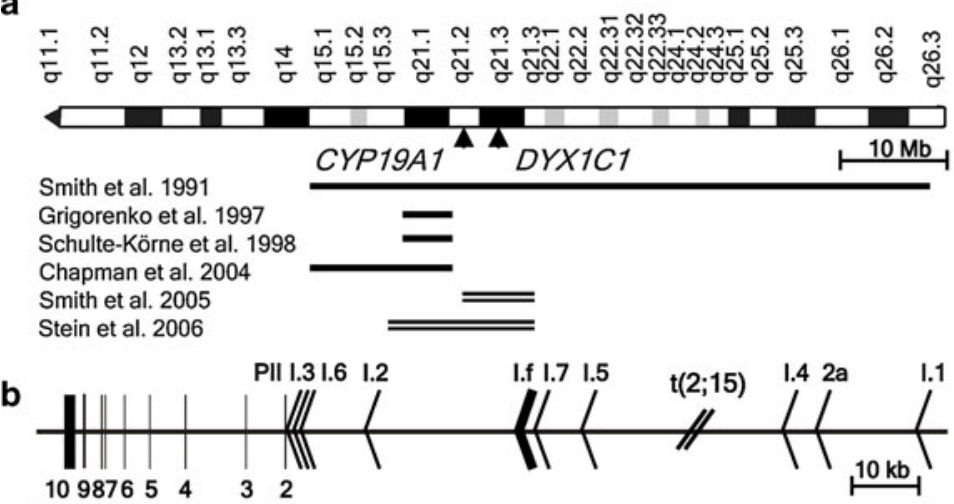

c
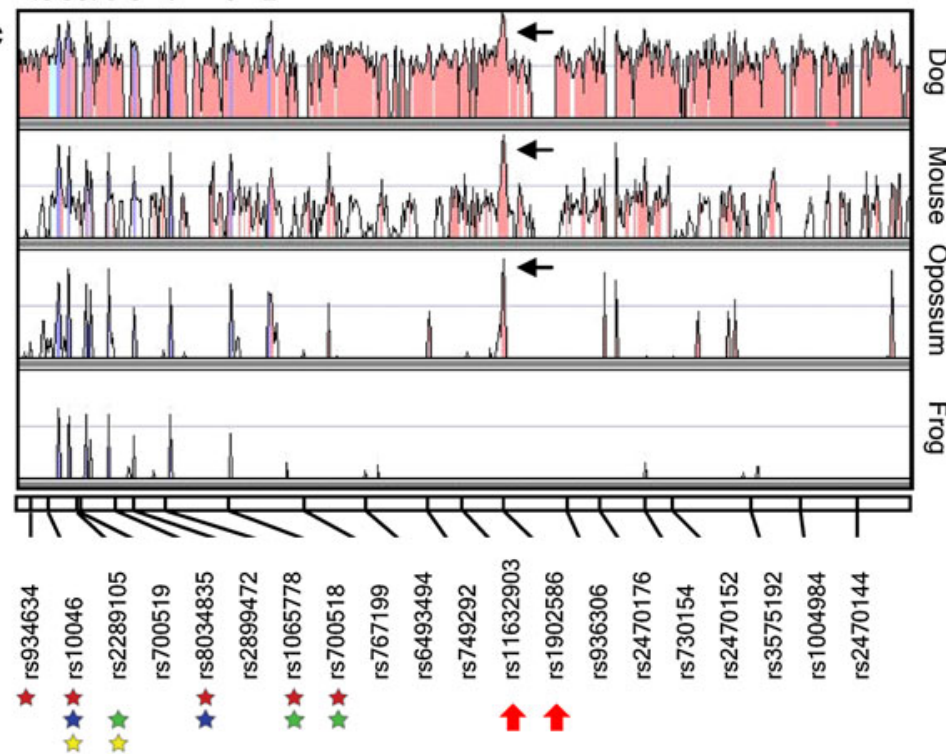

$\star \mathrm{OH}, \mathrm{US}$, SSD phonological processing

* OH, US, SSD oral motor skill

मे $\mathrm{OH}, \mathrm{US}, \mathrm{SSD}$ language

* GA, US, DYS reading measures

Fig. 2 The CYP19A1 locus on 15q21.2. a An overall map of chromosome $15 \mathrm{q}$ shows the relative positions of CYP19A1, DYX1C1 and the linkage peaks in different studies of dyslexia (solid lines) and SSD (double lines). b CYP19A1 gene organization, including coding exons (vertical bars), promoter regions (arrowheads), and the translocation $\mathrm{t}(2 ; 15)(\mathrm{p} 12 ; \mathrm{q} 21)$ breakpoint (slash). The brain-specific exon/promoter I.f is highlighted with a thicker arrowhead. The gene is located on the reverse strand and therefore is drawn from right $\left(5^{\prime}\right)$ to left $\left(3^{\prime}\right)$. c An evolutionary comparison of the CYP19A1 genomic sequence across four species (dog, mouse, opossum and frog) shows the highest conservation for the brain-specific exon/promoter I.f. The

underlining SNPs within the aromatase gene as genetic components common to dyslexia and SSD.

\section{Highly significant association to language and reading quantitative traits $(Q T s)$}

Based on the role of estrogens in the development of the song circuit in male songbirds, we hypothesized that d
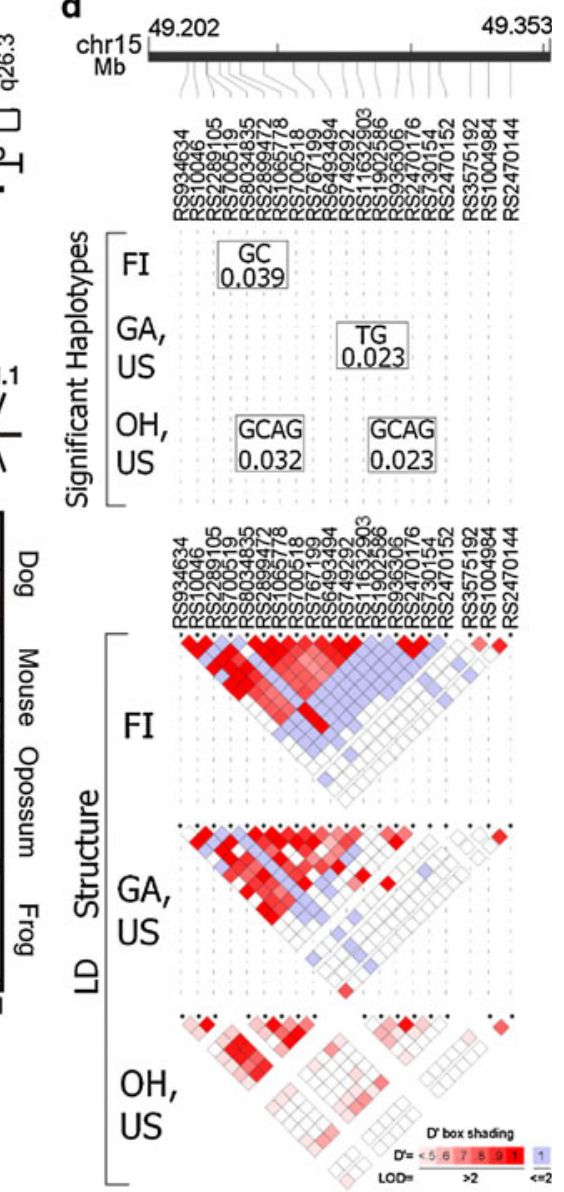

20 SNPs genotyped in this study are positioned along the gene on the lowest part of the evolutionary sequence comparison. The two SNPs flanking I.f and used in EMSA experiments are indicated by thick red arrows. Colored stars under SNPs are indicating a significantly associated QT to the corresponding marker. In the OH, US, SSD cohort, association to QTs such as phonological processing, oral motor skills and language, is marked with blue, green and yellow stars, respectively. Red stars indicate association to reading measures detected in the GA, US, DYS cohort. d Haplotypes associated with dyslexia as a categorical trait in three of the cohorts and the respective LD structures

variants in CYP19A1 might be associated with speech production and phonological processing. We thus initially focused our QTs analyses on the OH, SSD cohort. The variance component test of association was used (likelihood ratio test) because it was most suitable for QT analysis. Among our most significant results ( $p$-values significant at the 0.05 level after correction for multiple testing), were SNPs associated with the rate of repetition of 
Table 1 Description of participants by study and sex with complete genotype and phenotype information

\begin{tabular}{llllll}
\hline Cohort & Sex & Affected & Unaffected & Unknown & QTs \\
\hline FI, DYS & Female & 21 & 36 & 8 & NA \\
& Male & 29 & 27 & 9 & NA \\
GER, DYS & Total & 50 & 63 & 17 & NA \\
& Female & 78 & 27 & 384 & 350 \\
& Male & 340 & 21 & 383 & 297 \\
CO, US, DYS & Total & 418 & 48 & 767 & 647 \\
& Female & NA & NA & NA & 225 \\
& Male & NA & NA & NA & 228 \\
GA, US, DYS & Total & NA & NA & NA & 453 \\
& Female & 6 & 17 & 0 & 23 \\
& Male & 16 & 18 & 0 & 34 \\
IA, US, SLI & Total & 22 & 35 & 0 & 57 \\
& Female & NA & NA & NA & 240 \\
& Male & NA & NA & NA & 311 \\
OH, US, SSD & Total & NA & NA & NA & 551 \\
& Female & 135 & 95 & 5 & 235 \\
& Male & 133 & 179 & 3 & 315 \\
& Total & 268 & 274 & 8 & 550 \\
\hline
\end{tabular}

double syllables (oral motor skill) (rs2289105, $p=2 \times$ $10^{-6} ; \quad$ rs1065778, $p=4 \times 10^{-5} ;$ rs700518, $p=1 \times$ $10^{-7}$ ) and with the repetition of nonsense words (phonological processing) (rs10046, $p=5 \times 10^{-5}$; rs8034835, $\left.p=4 \times 10^{-5}\right) \quad$ (Fig. 2c; Supplementary Table 6). In addition, we found association between SNPs in this same region and vocabulary (rs10046, $p=7 \times 10^{-6}$; rs2289 105, $p=3 \times 10^{-5}$ ) (Fig. 2c; Supplementary Table 6) which is known to be correlated with phonological processing skills (Wise et al. 2007).

We also observed an association between some of these SNPs and reading skills measured in the GA, US, DYS cohort (Supplementary Tables 7 and 8). Among the most significant associations were those with the Woodcock reading mastery test-revised (WRMT-R) word attack subtest that measures skills in grapheme-phoneme correspondence by reading nonsense words (rs934634, $p=$ $9 \times 10^{-5} ;$ rs10046, $p=7 \times 10^{-4}$ ), the WRMT-R word identification subtest that measures reading of single real words (rs80347835, $p=3 \times 10^{-4}$ ), the Gray oral reading test-3rd edition (GORT-3) passages reading task (rs700 $518, p=4 \times 10^{-4}$ ) and the GORT-3 passage comprehension task (rs1065778, $p=6 \times 10^{-4}$ ) (Fig. 2c; Supplementary Tables 7 and 8). We did not observe any association between QTs and variants in CYP19A1 in the CO, US, DYS and GER, DYS cohorts, nor in the IA, US, SLI cohort. We did not have any QTs to test for association in the FI, DYS cohort. In conclusion, QT analysis of association of single SNPs showed highly significant association $\left(p<10^{-4}\right)$ in the $\mathrm{OH}, \mathrm{SSD}$ and the GA, DYS cohorts, for the measures of oral motor skills, vocabulary, phonological processing in the SSD cohort and reading in the DYS cohort. These associations are spread over the whole coding part of the aromatase gene, exons 2-10, approximately $30 \mathrm{~kb}$ in size (Fig. 2c).

Identification of a human-specific interspecies variation in an otherwise highly conserved gene

To further characterize the breakpoint region in relation to the disrupted aromatase gene, we proceeded with an evolutionary sequence analysis of both the complex promoter and the coding region of CYP19A1. The sequence of the brain-specific exon/promoter I.f displayed the highest conservation across a broad range of vertebrates, using GenomeVISTA alignment (Fig. 2c), which is not surprising as aromatase has been implicated in brain development in a broad range of species (Forlano et al. 2006). We sequenced the coding exons of CYP19A1, as well as its brain-specific exon/promoter I.f, in four non-human primate species (chimpanzee, bonobo, gorilla and orangutan) and detected 26 single base pair variants, different in human as compared to one or more of the non-human primates tested (Supplementary Table 1). However, only four amino-acid substitutions were found, all in the orangutan and none in the other primates, suggesting that CYP19A1 is functionally highly constrained (Supplementary Tables 1 and 2). Although we applied a likelihood ratio test to analyze the selection pressure for CYP19A1 during primate evolution, the low information content 

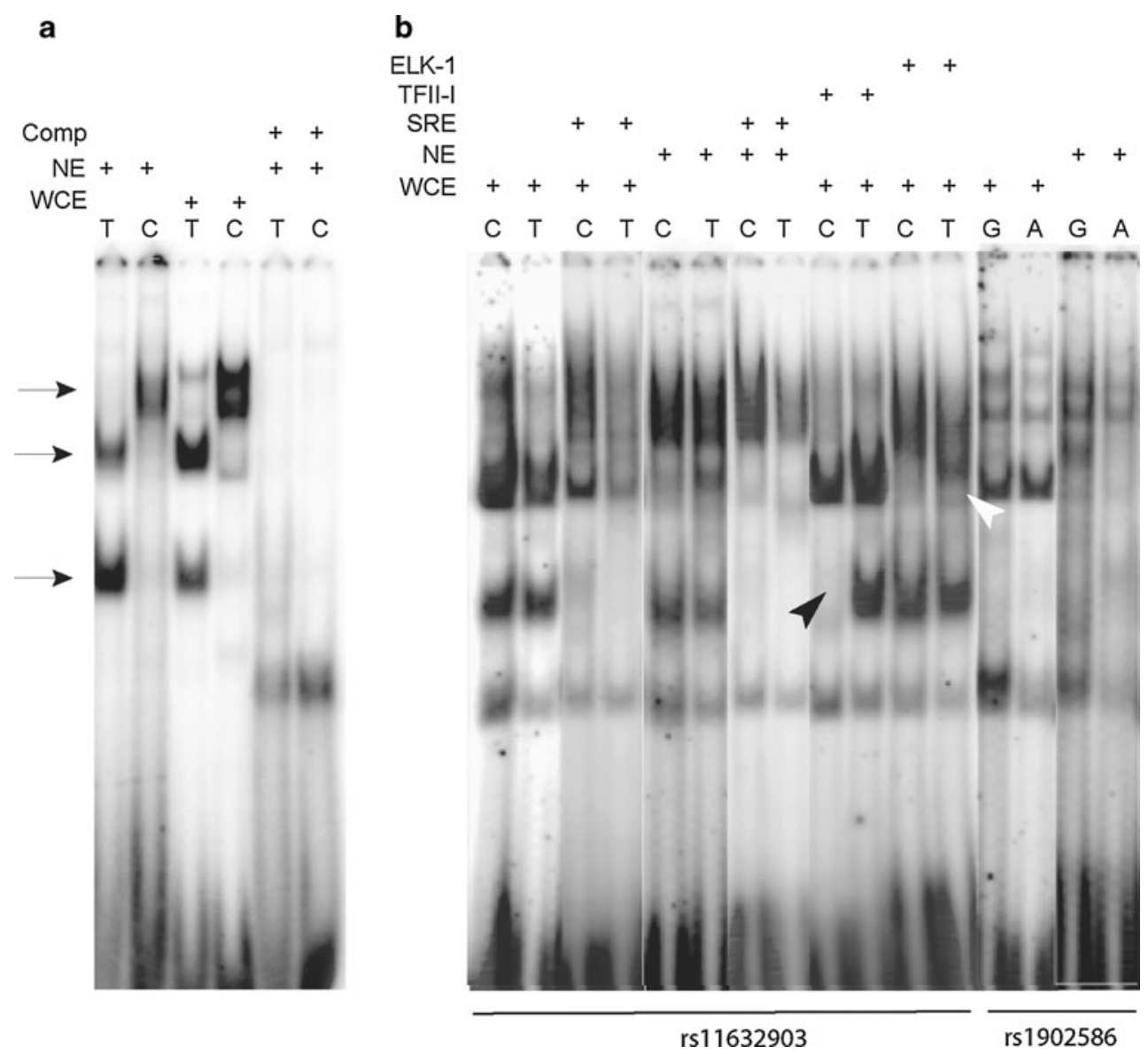

Fig. 3 EMSA showing the effects, on transcription factor binding, of the human-specific variant from exon/promoter I.f of CYP19A1 (a) as well as the effect of the two SNPs (rs11632903 and rs1902586) flanking I.f (b). Nuclear extracts (NE) and whole cell extracts (WCE) from the neuroblastoma cell line SH-SY5Y were used in EMSA. The specificity of all probes was confirmed by competition assays (Comp) with unlabeled probes (shown only in a). A "+" in the top of the EMSAs denotes the type of extracts and presence in the extracts of antibodies for supershifts or probes for competitions. a EMSA for the

drastically reduces the power and the estimates may not be completely reliable (Supplementary Tables 3 and 4).

Of the 26 sequence variants between human and the four non-human primates, we identified one variant that was different in humans as compared to all the other primates, including the sequences available in the public databases. This variant, a " $\mathrm{T}$ " in human and a " $\mathrm{C}$ " in all other primates, is located in the highly conserved brain specific exon/promoter I.f. Electrophoretic mobility shift assay (EMSA) experiments, using nuclear and whole-cell extracts from a human neuroblastoma cell line (SH-SY5Y), showed completely different retardation patterns for the human " $T$ " allele as for the non-human " $C$ " allele (Fig. 3a). In silico analysis of this sequence variant by TESS (www.cbil.upenn.edu/cgi-bin/tess/tess) and by the Genomatix SNP Inspector (www.genomatix.de) revealed a gain of transcription factor binding sites for the human-

human-specific variant from exon/promoter I.f. Arrows show differences in retardation patterns for the human- $(\mathrm{T})$ and the primate(C) specific alleles. b EMSA for the two genotyped SNPs flanking I.f; $C$ and $T$ denote the alleles of rs 11632903 and $G$ and $A$ of rs1902586, respectively. Predicted altered bindings of TFII-I and Elk-I to rs11632903 were verified by supershift assays (black and white filled arrowheads respectively) with specific antibodies, in WCE and by a consensus probe (SRE) to compete with the TFII-I binding site

specific allele ("T") in comparison to the non-human variant ("C"), for factors such as NEUROD1, Upstream stimulating factor $1 / 2$, E-box factor, TAL-1, DEP2, c-Myc and NF-kappaE2.

Two SNPs flanking the brain-specific exon/promoter I.f show differential binding of transcription factors

Among the SNPs genotyped in our material, rs11632903 (T/C) and rs1902586 (G/A) flank the brain-specific exon/ promoter I.f of CYP19Al and are located $\sim 5.8 \mathrm{~kb}$ downstream and $\sim 250 \mathrm{bp}$ upstream of I.f, respectively (Fig. 2c). We hypothesized that these alleles might have causative roles by affecting the binding of proteins and thus the regulation of transcription of aromatase in the brain. In silico predictions of altered transcription factor binding for both SNPs indicated differences in the number of hits as 

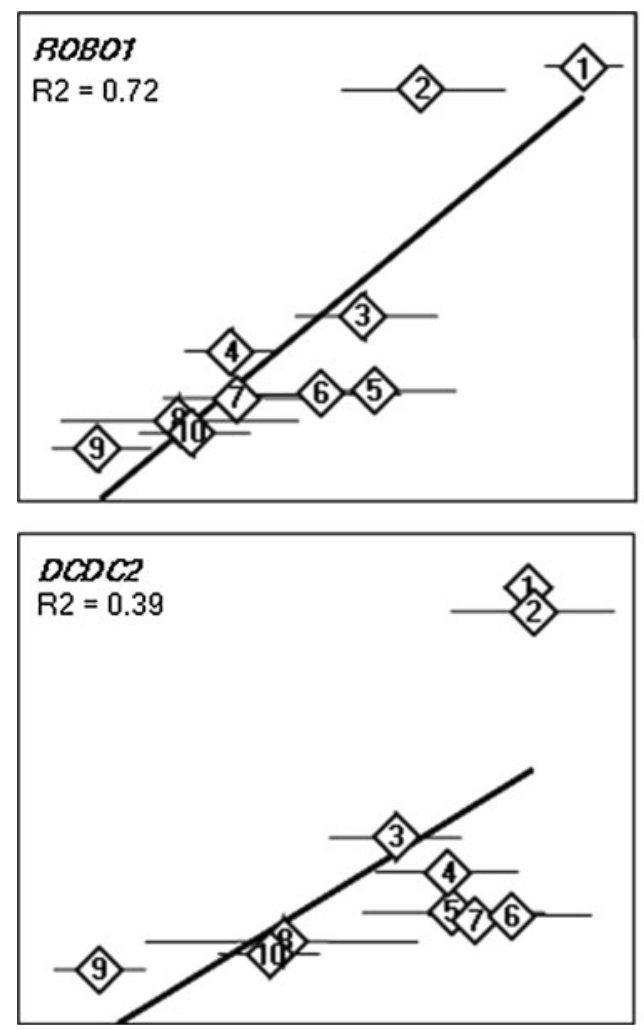

Fig. 4 Correlation of CYP19A1 (y-axis) mRNA expression to four dyslexia genes (ROBO1, DYX1C1, DCDC2, and KIAA0319; $x$-axis, respectively) in different regions of adult human brain. $X$ - and $y$-axes are in arbitrary $\log _{2}$ units. For clarity, the scales are not shown.

well as in the identity of the predicted binding factors. In particular, the "T" allele of rs11632903 abolished the GTF2I/TFII-I (General Transcription factor II-I) and Elk-I (ELK1, member of ETS oncogene family) binding sites that were present for the " $\mathrm{C}$ " allele. To verify these predicted effects, we used probes containing both alleles of these SNPs in EMSA; both SNPs showed reduced binding for the "T" in rs11632903 and the "A" in rs1902586 (Fig. 3b). TFII-I and ELK-1 bind differently with a "C" or a "T" of rs11632903 as seen by supershift assays (Fig. 3b, indicated by black and white arrowheads respectively). We also performed a competition assay with a probe from the well studied c-fos promoter, where the serum response element (SRE) binds to the TFII-I site (Kim et al. 1998). We observed a reduction of the TFII-I binding to both alleles (Fig. 3b).

Correlation of mRNA expression in regions of adult human brain for the aromatase and six dyslexia-associated genes

As the promoter analysis suggested similar transcription factor binding sites for CYP19A1 and the dyslexia
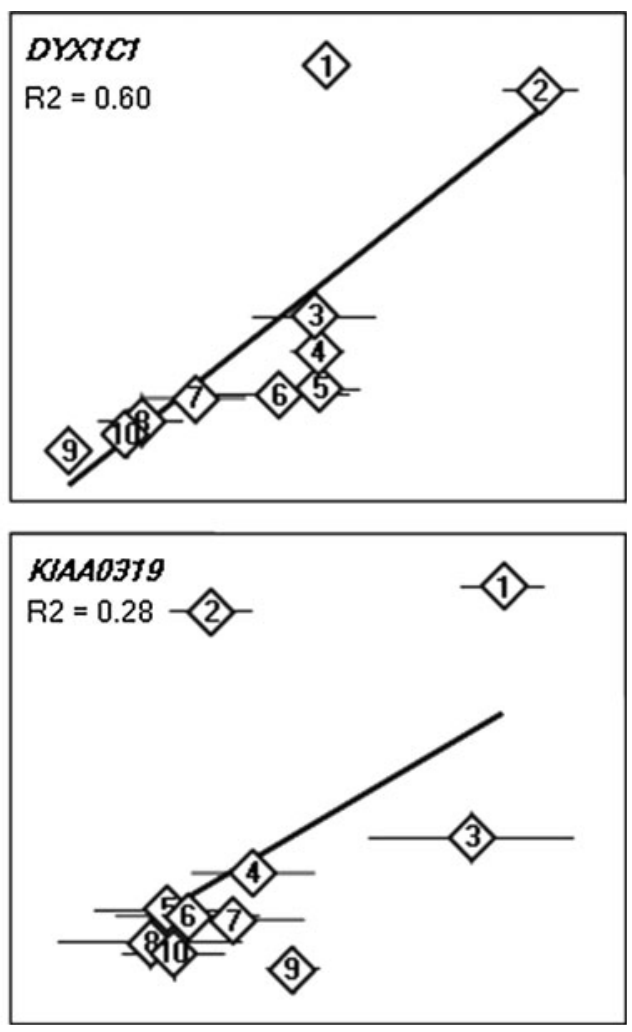

1 thalamus; 2 hypothalamus; 3 paracentral gyrus; 4 hippocampus; 5 temporal cortex; 6 frontal cortex; 7 parietal cortex; 8 occipital cortex; 9 postcentral gyrus; 10 whole brain

susceptibility gene $D Y X 1 C l$, we studied the expression levels of CYP19A1 and the six dyslexia-associated genes reported so far. Nine sub-regions of the adult human brain were studied using quantitative real-time RT-PCR. All genes showed the highest expression in the hypothalamus or thalamus and an overall correlation across all brain regions (Fig. 4). The expression of CYP19A1 showed strongest correlation with $R O B O 1$ and $D Y X 1 C 1\left(R^{2}=0.72\right.$ and $R^{2}=0.60$, respectively), while much weaker with $D C D C 2 \quad\left(R^{2}=0.39\right)$ and C2ORF3 $\left(R^{2}=0.36\right)$ and weakest with KIAA0319 $\left(R^{2}=0.28\right)$ and MRPL19 $\left(R^{2}=\right.$ $0.20)$ (data not shown for C2ORF3 and MRPL19).

Testosterone-induced neuronal process outgrowth requires aromatase

To directly study the role of aromatase function on neurite outgrowth in undifferentiated neurons, we investigated process outgrowth of rat E17 hippocampal neurons in culture. Testosterone and estradiol-17 $\beta$ both significantly promoted neurite outgrowth at day 4 in culture when compared to controls (Fig. 5a), also in accordance with previous reports (see review McEwen et al. 1991). 

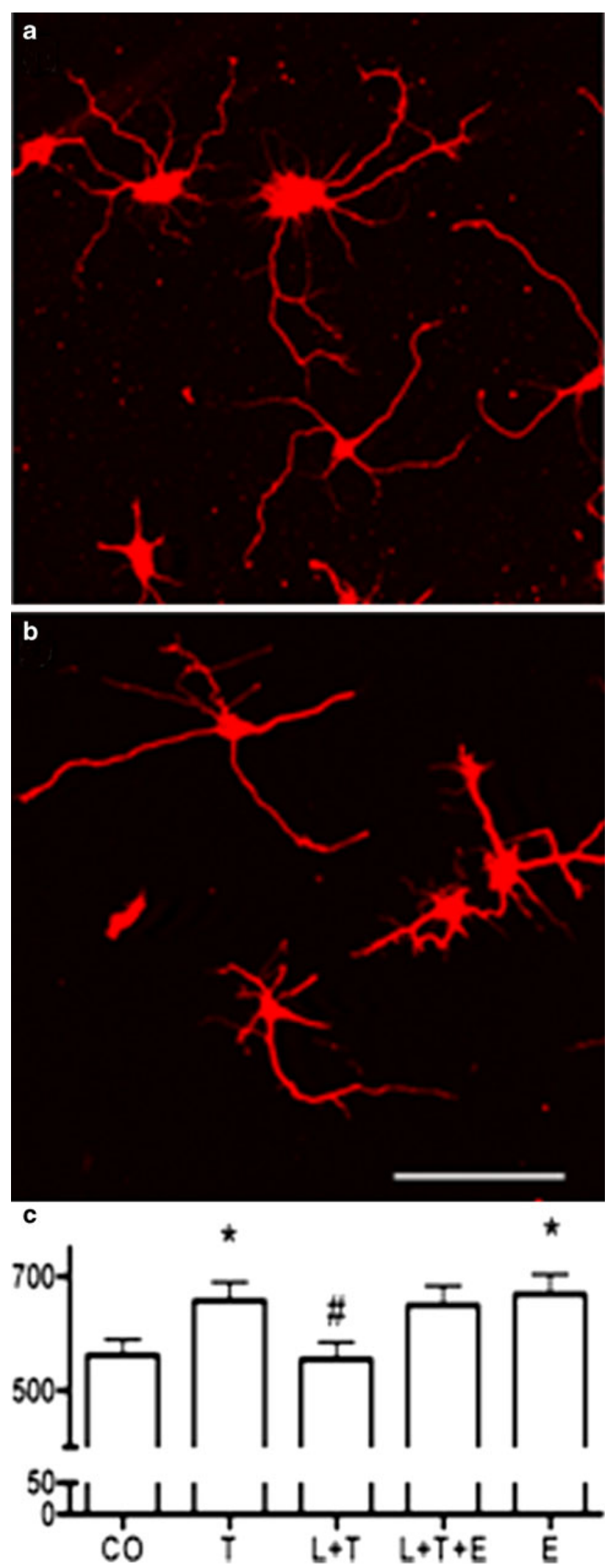

The effect of testosterone was blocked by the aromatase inhibitor letrozole (Fig. 5b). However, letrozole did not block the effects of estradiol and testosterone together,
Fig. 5 Testosterone enhances neuronal process outgrowth in an aromatase-dependent manner. E17 rat embryonic hippocampal neurons cultured for 4 days with testosterone (a) or with testosterone and the aromatase inhibitor letrozole (b), and stained with the neuronal marker TuJ1 (red). c Total neurite outgrowth in $\mu \mathrm{m} /$ neuron. The measurement shows the effects of solvent $(C O)$, testosterone $(T)$, letrozole $(L)$, estradiol-17 $\beta(E)$. Letrozole inhibited testosteroneinduced outgrowth $(L+T)$, but did not inhibit the effects of estradiol$17 \beta$ and testosterone together $(L+T+E)$. Letrozole alone had no significant effects on neurite outgrowth. Similar effects were observed with a 3-day treatment (data not shown). $* P<0.05$ against control, ${ }^{\#} P<0.05$ against $\mathrm{T}$ and $\mathrm{L}+\mathrm{T}+\mathrm{E}$ (ANOVA followed by $t$-test)

indicating that aromatase-dependent conversion of testosterone to estradiol enhances neurite outgrowth in cultured hippocampal neurons (Fig. 5c).

Aromatase knockout mice show cortical disorganization

To study the role of CYP19A1 in brain development, we performed a structural analysis of the brain in aromatase knockout (ArKO) mice. As shown in Fig. 6, we observed several signs of cortical disorganization in the ArKO mice as compared to wild-type (WT) controls. The neuronal density in cortical areas was significantly increased at embryonic day 17.5 (E17.5) (Fig. 6a). ArKO E17.5 mice showed also an increased signal for the epidermal growth factor (EGF) (Fig. 6b) which plays an important role in the regulation of cell growth, proliferation and differentiation. Remarkably, even in mature mice, the ArKO cortical areas had an increased neuronal density in cortical layers II/III as determined by the neuron-specific nuclear protein $(\mathrm{NeuN})$ staining (Fig. 6c) and systematic cell quantification (Fig. 6f). No statistical differences between genotypes were found in other cortical layers. Moreover, an increased number of parvalbumin-positive inhibitory interneurons (Fig. 6d, e) and occasional cortical heterotopias (data not shown) were observed. The mid-sagittal areas of the anterior and hippocampal commissures (HC) as well as corpus callosum (CC), were similar in size in ArKO and WT mice (Supplementary Table 5).

\section{Discussion}

We mapped the translocation breakpoint in a dyslexic individual carrying $\mathrm{t}(2 ; 15)(\mathrm{p} 12 ; \mathrm{q} 21)$ (Nopola-Hemmi et al. 2000) to the complex promoter region of CYP19A1 that encodes the enzyme aromatase. In humans, the aromatase CYP19Al gene stretches $\sim 123 \mathrm{~kb}$ in the $15 \mathrm{q} 21.2$ region, with a regulatory and $5^{\prime}$ UTR region of $93 \mathrm{~kb}$, and a coding region (exons $2-10$ ) of $\sim 30 \mathrm{~kb}$. Its expression is regulated in a tissue- or signalling pathway-specific manner by mean 

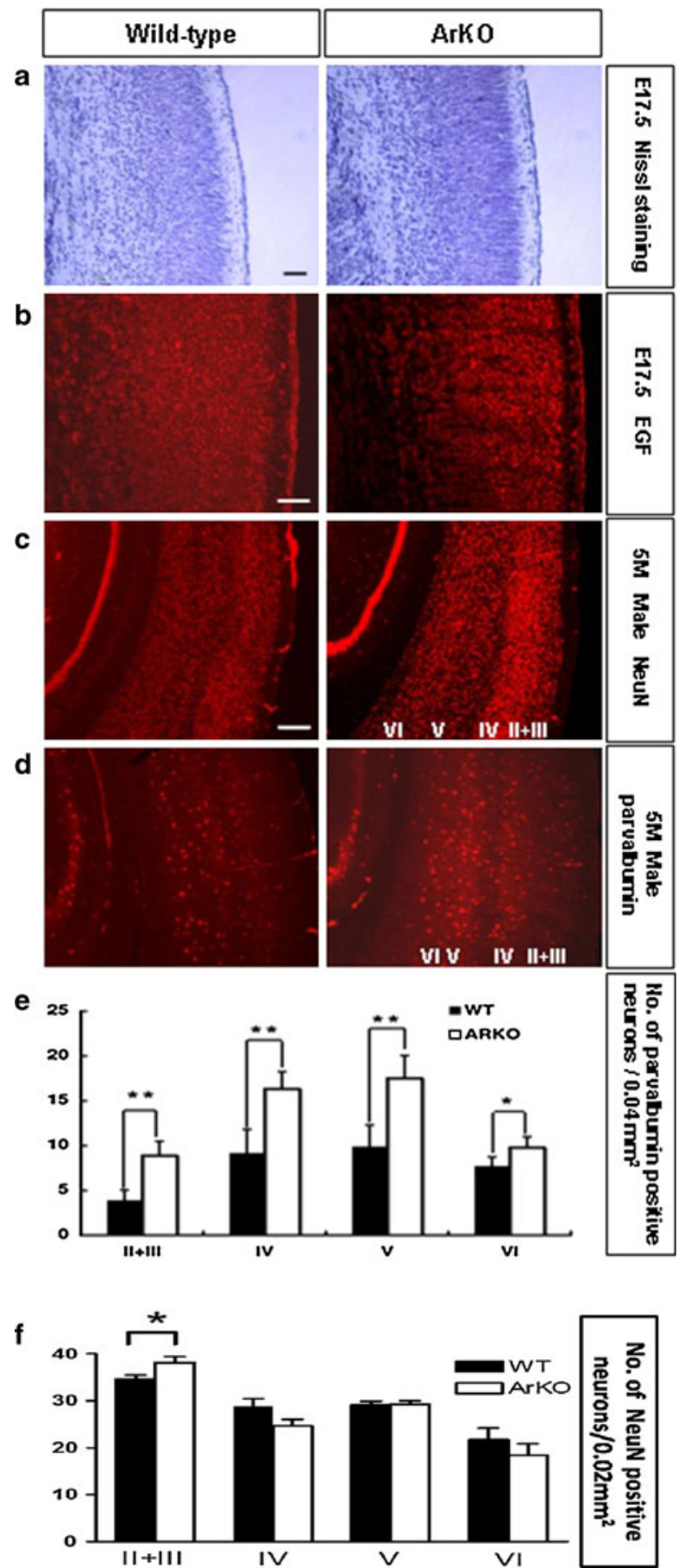

Fig. 6 Cortical disorganization in ArKO mice as compared to WT. Increased neuronal density (a) and EGF signal (b) at E17.5 in the somatosensory cortex of ArKO mice vs. WT. Increased neuronal density (c) and parvalbumin-positive interneurons (d) in 5 months-old male ArKO mice vs. WT. (a cell body in blue; b EGF-positive cells in red; c neurons (NeuN-positive) in red; d parvalbumin-positive interneuron in red). (e) Mean number of parvalbumin-positive interneurons in the layers II-VI of the somatosensory cortex in 5 months-old male ARKO mice. (f) Mean number of NeuN positive neurons in the layers II-VI of the somatosensory cortex in 5 months-old male ArKO and WT. Student's $t$-test: $* P<0.05$; $* * P 0.01$. Scale bars a $50 \mu \mathrm{m}$; b $50 \mu \mathrm{m}$; c and d $200 \mu \mathrm{m}$ of at least ten different exon 1/promoters (Bulun et al. 2004; Boon et al. 2010). The exon/promoter I.f is the brainspecific first exon/promoter located $\sim 33 \mathrm{~kb}$ upstream of exon 2 and it has exactly the same length in human and mouse (139 bp) with a 94\% sequence homology (Chow et al. 2009). This is by far the strongest human/mouse homology found in the different first exons/promoters of this gene, far greater than the $88.5 \%$ homology found for the ovary- and adipose tissue-specific exon/promoter 1.3.

Our evolutionary analysis of the CYP19A1 genomic region also revealed a high level of conservation of the brain-specific exon/promoter I.f across a wide range of vertebrates, and as noted previously, it has been shown to be conserved in the songbird Zebra finch as well (Ramachandran et al. 1999). Interestingly, we identified a human-specific variation within this highly conserved brain-specific exon I.f, when comparing human and nonhuman primates. This variant showed different patterns of protein binding in EMSA experiments, and in silico analysis predicted differential binding of factors such as NEUROD1, Upstream stimulating factor $1 / 2$, E-box factor, TAL-1, DEP2, c-Myc and NF-kappaE2. Interestingly, NEUROD1 is involved in neurogenesis, the Scl/TAL-1 transcription factor has been shown to play a key role in neuronal development (Ogilvy et al. 2007) and in Drosophila, DEP2 is binding to a steroid hormone receptor like protein (Ayer and Benyajati 1992). Further experimental studies will be needed in order to identify the true factor(s) binding to this site and regulating CYP19A1 expression in the human brain.

The fact that the two SNPs, rs11632903 and rs1902586, that flank exon/promoter I.f, are moderately associated with dyslexia as a categorical trait in the GA, DYS cohort as a 2-marker haplotype, suggests that this very specific exon/promoter I.f might have a role in the risk for development of dyslexia. Moreover, these two variants also showed allele-specific differential binding for transcription factors such as TFII-I and Elk-1. TFII-I downregulates estrogen-responsive genes through interaction with estrogen receptor $\alpha(E R \alpha)($ Ogura et al. 2006). Elk-1 has been shown to have a role in learning and memory in rats (Cammarota et al. 2000). Interestingly, both of these factors also show altered binding for dyslexia-associated alleles at the $5^{\prime}$ UTR of the DYXICl gene (Tapia-Paez et al. 2008), one of the main loci (DYX1) implicated in dyslexia.

Our results from the QTs analysis of speech and reading measures with regard to SNPs covering the CYP19A1 gene and its entire promoter region, gave highly significant association in two (OH, US, SSD and GA, US, DYS) of the five cohorts for which QT measures were available. Specifically, we detected associations in the GA, US, DYS cohort for reading and in the OH, US, SSD cohort for measures of speech (e.g., oral motor skills, vocabulary and 
phonological processing). These findings support the possibility of a common mechanism for dyslexia and SSD, and the aromatase gene is, to our knowledge, the first gene which has shown association with cognitive skills related to both phenotypes. The fact that we did not observe any significant associations in the other three cohorts (GER, DYS; CO, US, DYS; IA, US, SLI) is not unusual for an association study of complex traits such as dyslexia, SLI or SSD. The cohorts from our study originate from different geographical locations, and even if these populations are primarily Caucasians, we cannot exclude the possibility that they have different genetic lineages. Therefore, the association of the aromatase gene to the reading or language-related measures we tested may not be uniform across the cohorts due to differential linkage disequilibrium (LD) between a causal variant and the genotyped SNPs, or to the actual effect size of the gene varying between cohorts (Vieland 2001). Moreover, a rare variant might be especially difficult to detect, even in cohorts drawn from a single larger population.

Aromatase is responsible for the irreversible conversion of androgens into estrogens in the developing and mature brain. Aromatase and estrogens, which can be locally produced in several tissues other than the gonads including the central nervous system, have been shown to be essential for the development of the mammalian brain, with several important roles in processes such as neuronal proliferation and migration, dendritic branching, brain plasticity and apoptosis (Beyer 1999; Forlano et al. 2006; Garcia-Segura 2008; Boon et al. 2010; Azcoitia et al. 2011). In mice of both sexes, aromatase expression level is much higher in the developing brain than in adults (Karolczak et al. 1998; Bakker et al. 2004), at a time point when the neural architecture of the brain is being determined. Our results on neuronal cultures give further support to a central role for the local aromatase activity and estrogen production in brain development (Saldanha et al. 2009). We demonstrate here that, in embryonic rat hippocampal cultures, the neurite outgrowth induced by testosterone is solely aromatasedependant. Human aromatase deficiency is a very rare phenomenon and, to date, only 15 male and female cases have been reported (Jones et al. 2007; Lanfranco et al. 2008). However, these reports lack any description of the patient's cognitive functions. As rodent ArKO models are available, we performed a detailed analysis of brain morphology in ArKO mice. Several signs of cortical disorganization were observed, including increased neuronal density in cortical areas and occasional cortical heterotopias. These structural abnormalities have been previously observed in the postmortem brain of dyslexic individuals (Galaburda et al. 1985) and have also been documented in rat brains where Dyxlcl has been knocked-down by RNA interference (RNAi) (Rosen et al. 2007). Interestingly, similar to the ArKO mice, cortical disorganization, characterized by increased neuronal density was also observed in the brain of mice carrying a knockout of Robol, another of the dyslexia-susceptibility genes (DYX5 locus) (Andrews et al. 2006). In addition, RNAi downregulation of the dyslexia-susceptibility genes Dcdc2, Kiaa0319 and Dyxlc1 in rat embryos also affects neuronal migration to cortex (Meng et al. 2005; Paracchini et al. 2006; Wang et al. 2006). Our finding that aromatase may be necessary for neurite outgrowth in embryonic rat hippocampal cultures and for the correct structure of the cortex in mice brain, is another line of evidence supporting the importance of the CYP19A1 gene/product in brain development. When we consider this finding alongside with findings regarding the phenotypes observed in rodents where dyslexia genes were knocked-down and the anatomical findings from human dyslexic brains, it suggests that CYP19A1 may be a significant factor in the development of the brain in areas relevant to the ability to learn and use written and spoken language.

\section{Methods}

\section{Ethics statement}

In this study, all research involving human participants has been properly approved by respective ethical boards from each university involved. Written consent, or assent in case of children, was obtained from all participants. The study of the Finnish dyslexia cohort was approved by Finnish ethical committees in Helsinki and Jyväskylä, Finland, as well as by the Karolinska Institutet, Stockholm, Sweden. The study of the German dyslexia cohort, recruited from the Departments of Child and Adolescent Psychiatry and Psychotherapy at the Universities of Marburg and Würzburg, was approved by the respective ethics committees. The research involving the participants in the Colorado dyslexia cohort was approved by the Institutional Review Boards of the University of Colorado, Boulder, and the University of Nebraska Medical Center. Informed consent or assent was obtained from participating adults and children respectively. For the study of the Georgia dyslexia cohort, human subject procedural approval was provided by the Institutional Review Boards of the Universities of Georgia and Purdue, USA. The study of the Iowa SLI cohort was approved by the University of Iowa Internal Review Board prior to initiation. The parents of all children were informed and provided written consent for behavioral assessment and collection of DNA from their children. The Ohio SSD cohort was approved by the University Hospital Institutional Review Board, affiliated with Case Western Reserve University. The mouse animal work (ArKO mice) was approved by the Howard Florey Institute Animal Ethics Committee, Australia (approval ID 08-070) 
and by the Stockholm's South Animal Ethics committee, Sweden (approval ID S127-08). The rat hippocampal neuronal culture is under license number ESLH-2007-09085/ Ym-23 to E. Castrén.

\section{Cohorts}

See Table 1 for a more detailed description of each the six cohorts studied.

\section{Finnish dyslexia cohort (FI, DYS)}

Nineteen Finnish three-generation families (130 subjects; Table 1), of Caucasian origin and whose phenotypes were ascertained as previously described (Nopola-Hemmi et al. 2001), were genotyped (Kaminen et al. 2003; Anthoni et al. 2007).

The $\mathrm{t}(2 ; 15)(\mathrm{p} 13 ; \mathrm{q} 22)$ family has been described phenotypically in detail previously (Nopola-Hemmi et al. 2000). Genomic DNA was obtained from blood lymphocytes using a standard non-enzymatic extraction method (Lahiri and Nurnberger 1991).

\section{German dyslexia cohort (GER, DYS)}

A total of 411 trios of German Caucasian origin $(1,233$ individuals totally; Table 1) were genotyped. All individuals, and in case of children younger than 14 years, their parents, gave written informed consent to participation in the study. The families were recruited from the Departments of Child and Adolescent Psychiatry and Psychotherapy at the Universities of Marburg and Würzburg. The diagnostic inclusion criteria and phenotypic measures have been described in detail previously (Schulte-Korne et al. 1996, 2001, 2007; Ziegler et al. 2005; Schumacher et al. 2006). Briefly, the diagnosis of dyslexia was based on the spelling score using the $\mathrm{T}$ distribution of the general population. Based on the correlation between IQ and spelling of 0.4 (Schulte-Korne et al. 2001), an anticipated spelling score was calculated. The child was classified as dyslexic if the discrepancy between the anticipated and the observed spelling score was at least one standard deviation. Probands and all siblings fulfilling the inclusion criteria were assessed with several psychometric tests. These tests targeted different aspects of the dyslexia, i.e. word reading, phonological awareness and short term memory (see Supplementary Table 9).

\section{Colorado dyslexia cohort (CO, US, DYS)}

This population was recruited through the Colorado Learning Disabilities Research Center and included 216 nuclear families with a total of 880 genotyped individuals
(Table 1). Ascertainment and evaluation of this population has been described previously (DeFries et al. 1997). Briefly, families were selected through twins living in Colorado, at least one of whom had a history of reading problems by school report and confirmed by school records. Exclusion criteria included a full scale IQ score less than 80 and any sensory or medical problems that would interfere with reading. The twins and available siblings were given an extensive battery of assessments of reading, spelling, phonology, orthography, rapid naming, and intelligence. Measures used in the current analyses are given in Supplementary Table 9. DNA was obtained by extraction from blood, buccal swabs, or more recently from saliva samples. This sample set is made up of $\sim 89 \%$ Caucasian, $\sim 3 \%$ African-American, Asian, or Native American, and $\sim 8 \%$ self-identified as mixed.

\section{Georgia dyslexia cohort (GA, US, DYS)}

Seventeen Caucasian families of US Caucasian origin and consisting of 57 subjects (Table 1) were studied. Families were recruited and referred through schools, physicians, and community announcements at the Center for Clinical and Developmental Neuropsychology (CCDN) at the University of Georgia. All qualifying families had at least one proband between the ages of 8 and 12 years with significant reading problems and no history of neurological impairment, traumatic brain injury, psychiatric disorders, or severe pre- and/ or perinatal complications. All parents provided informed consent for the neuropsychological evaluation of themselves and their children. The test battery consisted of measures designed to assess intelligence, academic achievement, receptive and expressive language, phonological processing, memory, reading, spelling, visual-spatial ability, executive functioning, handedness, and social-emotional functioning (see Supplementary Table 9 for a full description of the tests used). Genomic DNA was obtained from buccal swabs by an $\mathrm{NaOH}$ extraction method (Walker et al. 1999). Whole genome amplification of the extracted DNA was performed by the improved primer preamplification method (I-PEP-L) (Hannelius et al. 2005).

\section{Specific language impairment cohort (IA, US, SLI)}

The Iowa cohort consisted of 573 participants of Caucasian origin, all members of an ongoing longitudinal study of children with SLI (Table 1) and a control group of typically developing age mates. The longitudinal cohort was obtained from a large population sample $(N=7,206)$ of monolingual English speaking kindergarten-age children from Iowa, who participated in a cross-sectional epidemiologic study of SLI. All children had normal hearing and no diagnosis of neurodevelopmental disorders. A description of the sampling 
methods for the original cross-sectional sample and selection of the longitudinal sample have been described previously (Tomblin et al. 1997, 2000). The members of this longitudinal cohort initially consisted of 604 children and slightly more than one-third presented with language impairment as 6-year-olds, and the remaining represented a random sample of typically developing age-mates. At the beginning of second grade, blood, saliva or buccal samples were obtained from the children and their parents. The phenotypic data for the current study were collected when the participants were in kindergarten and later in second grade. The speech sound production data were obtained when the children were in kindergarten. The remaining behavioral phenotypic measures including receptive and expressive language were obtained in second grade at which time the children had been receiving reading instruction for approximately 2 years (see Supplementary Table 9 for a full description of the measures used).

\section{Speech sound disorder cohort (OH, US, SSD)}

One-hundred-and-eighteen Caucasian families of US origin consisting of 550 subjects (80 affected with both SSD and dyslexia, 147 affected with only SSD, 41 affected with only dyslexia, 274 unaffected with either SSD or dyslexia and eight of unknown phenotype) were genotyped (Table 1). Probands were enrolled in speech-language therapy for a moderate to severe speech sound production disorder. Children were also required to have normal hearing, intelligence, and speech mechanism (adequate oral structures for producing speech sounds). An extensive battery of standardized speech sound production, receptive and expressive language, reading decoding and comprehension, spelling, oral-motor skills, memory, and phonological processing measures were administered to all probands and their siblings of 4 years of age and older (see Supplementary Table 9 for a listing of the specific measures). Genomic DNA was obtained from self-collected buccal swabs or blood draws.

\section{Comparison of the SSD and SLI phenotypes to the dyslexia phenotypes}

As seen in Supplementary Table 9, comparable domains were assessed for the Georgia dyslexia (GA, US, DYS), SSD (OH, US, SSD) and SLI (IA, US, SLI) cohorts where language, reading, spelling and phonological processing were measured.

\section{FISH and Southern blotting}

For the mapping of the translocation breakpoints, $10 \mathrm{BAC}$ clones from chromosome 2 (RP11-502A5, -419E14,
-332A19，-89C12，-236I9，-521014，-351F21，-1290B4, -548D17 and -513019; BACPAC Resource Center (BPRC) at Children's Hospital Oakland Research Institute, Oakland, CA, USA) and 12 clones from chromosome 15 (RP11-10D13, -13H19, -56B16, -96N2, -108K3, -145A4, $-209 \mathrm{~K} 10,-394 \mathrm{~B} 5,-430 \mathrm{~B} 1,-519 \mathrm{C} 12,-522 \mathrm{G} 20$ and -540E17; Genome Systems, St Louis, MO, USA) were used as probes in FISH. Bacterial cultures and DNA isolation were performed according to standard protocols and probes were labeled by nick translation with FITC-dUTP (NEN Life Science Products, Boston, MA, USA), SpectrumOrange-dUTP (Vysis Inc, Downers Grove, IL), or biotin-14-dATP (detection with avidin conjugated FITC). FISH-analyses were performed according to standard protocols and the slides were analyzed on a Zeiss Axioplan 2 epifluorescence microscope (Carl Zeiss, Göttingen, Germany). Images were captured using a cooled CCD camera (Sensys Photometrics, München, Germany) and SmartCapture 2 (DigitalScientific Ltd., Cambridge, UK) or ISIS software (Metasystems GmbH, Altlussheim, Germany).

Genomic DNA $(15 \mu \mathrm{g})$ from the individual carrying the translocation and from an unrelated control were digested with BamHI, EcoRI, HindIII, KpnI, SacI, ScaI and SphI and subjected to electrophoresis and Southern hybridization as previously described (Taipale et al. 2003). PCRamplified genomic fragments from non-repetitive regions of the BAC clone RP11-108K3 were used as hybridization probes. PCR and labelling reactions were performed as previously described (Hannula-Jouppi et al. 2005).

Putative genes/exons from the $200 \mathrm{~kb}$ BAC clone spanning the breakpoint on chromosome 2 were in silico predicted using Genscan (genes.mit.edu/GENSCAN.html) and GrailEXP (grail.lsd.ornl.gov/grailexp). The expression of each of the 19 predicted genes/exons were tested by PCR on human cDNA libraries from fetal brain (cat. No. HL5504u, Clontech and cat. No. 052001b, Stratagene) and from leukocytes (cat. No. HL5509u and HL5019t, Clontech).

\section{Genotyping}

In the Finnish (FI, DYS) and Georgia (GA, US, DYS) dyslexia cohorts, 20 SNPs (Fig. 2c, lowest part of the panel) were genotyped using matrix-assisted laser desorption/ionization time-of-flight (MALDI-TOF) mass spectrometry as previously described (Peyrard-Janvid et al. 2004). PCR assays and extension primers were designed using the SpectroDESIGNER software (Sequenom). The same procedure was applied to the German (GER, DYS) cohort for 16 of those 20 SNPs (all except rs934634, rs700519, rs749292 and rs3575192).

For the Colorado dyslexia (CO, US, DYS), the SSD (OH, US, SSD) and the SLI (IA, US, SLI) cohorts, 
genotype data for 16 of those 20 SNPs (all except rs700519, rs6493494, rs749292 and rs3575192) were successfully generated using the $5^{\prime}$ exonuclease TaqMan Assay by Design or Assays in Demand from Applied Biosystems (Foster City, CA, USA). Real-time PCR was conducted using the ABI 7700HT system. Genotypes were assigned with the SDS 2.0 software (Applied Biosystems).

CEPH genomic DNA, negative controls and replicates of some samples were included on each plate to assure consistency of the genotype calls. Discrepancies in genotype calls and Mendelian errors were identified using the PEDCHECK (O'Connell and Weeks 1998) and the MARKERINFO from the S.A.G.E. program package. All genotypes were independently confirmed by two investigators. Genotyping results were also cross-validated by duplicate genotyping of 10-96 samples across the different laboratories. Allele frequencies were also checked to match across the different data sets.

\section{Statistical methods}

Testing for Hardy-Weinberg equilibrium was done via a Chi-squared goodness-of-fit test using only the founders to eliminate the non-independence owing to family data. Intermarker $\mathrm{LD}$ was visualized and pairwise $R^{2}$ values were determined using the Haploview v3.2 software (Barrett et al. 2005).

PDTPHASE v2.4 from the software package UNPHASED (Dudbridge 2003) was used to test for both single SNP and haplotype association with binary traits in all three populations, i.e. Finnish, German and North-American. This program is an implementation of the original PDT (Martin et al. 2000) but allowing missing data. Haplotypes were looked at in two- to four-marker sliding window.

A variance-component model developed for familybased association was used to assess single SNP significance of QTs in the GA, US, DYS and OH, US, SSD cohorts, as well as in both cohorts combined. This method assesses association between a marker and phenotype, while simultaneously estimating residual and multifactorial (polygenic, familial, and marital) variance components. Age was found to be significant in both populations and therefore was included in the baseline model as a covariate. At each SNP and for each trait, we tested for an additive, a dominant or a recessive allele effect. These three tests are correlated with each other and, because any two of these null hypotheses imply the third, they effectively count as two independent tests (Elston et al. 1999). Therefore, in each population and for each trait, the total number of independent tests performed is equal to twice the number of SNPs genotyped. To account for these multiple tests when determining allelic association to a trait, Sidak's correction was used (Sidak 1967).
Because the same reading test (WRMT-R, see Supplementary Table 9) was administered to participants in the GA, US, DYS and the OH, US, SSD cohorts, and the definition of dyslexia used to classify participants as affected was identical across the two cohorts, we combined $p$-values from tests of allelic association using Fisher's method (Fisher 1948).

Evolutionary analysis of the CYP19A1 genomic sequence

Evolutionary comparison of the $\sim 123 \mathrm{~kb}$ CYP19A1 genomic region, covering the full promoter as well as the coding region of the gene was performed using the GenomeVISTA browser (pipeline.lbl.gov/cgi-bin/GenomeVista). The human sequence $(49,285,000-49,420,000 \mathrm{bp}$ on chromosome 15, NCBI Build 36.1) was aligned with the genomic sequences of dog (Canis familiaris), mouse (Mus musculus), opossum (Monodelphis domestica) and frog (Xenopus tropicalis).

Evolutionary analysis of the CYP19A1 coding sequence

Chimpanzee (Pan troglodytes), pigmy chimpanzee (Pan paniscus), gorilla (Gorilla gorilla) and orangutan (Pongo pygmaeus) (DNA samples kindly provided by Kathrin Koehler, Max Planck Institute of Evolutionary Anthropology, Leipzig, Germany) orthologues were screened for variations by direct sequencing with human-specific, intronic primers (all primer sequences available on request). All nine coding exons and the brain-specific exon/promoter I.f of CYP19A1, including $100 \mathrm{bp}$ of flanking sequence, were PCR-amplified in $25 \mu \mathrm{l}$ reactions containing $20 \mathrm{ng} \mathrm{DNA}, 1.5 \mathrm{mM} \mathrm{MgCl}$, $0.4 \mathrm{mM}$ of each dNTP, $1 \mu \mathrm{M}$ of each primer and $0.03 \mathrm{U} / \mu \mathrm{l}$ of HotStarTaq DNA polymerase (Qiagen). We used a touchdown protocol with 42 cycles of amplification with $1^{\circ} \mathrm{C}$ decrease in annealing temperature at each round. The amplification started with two cycles at 63 and $62^{\circ} \mathrm{C}$ respectively, followed by three cycles at each temperature between 61 and $56^{\circ} \mathrm{C}$, and ending by 10 cycles at 55 and $54^{\circ} \mathrm{C}$, respectively. PCR cycles had an initial denaturation at $95^{\circ} \mathrm{C}$ for $15 \mathrm{~min} ; 30 \mathrm{~s}$ for each annealing and $30 \mathrm{~s}$ to $1 \mathrm{~min} 30 \mathrm{~s}$ elongation at $72^{\circ} \mathrm{C}$; and a final extension of $10 \mathrm{~min}$ at $72^{\circ} \mathrm{C}$. PCR products were dephosphorylated by $0.4 \mathrm{U} / \mu \mathrm{l}$ shrimp alkaline phosphatase (Amersham Biosciences/GE) and $2 \mathrm{U} / \mu \mathrm{l}$ exonuclease I (New England BioLabs), and were further sequenced using DYEnamic ET Dye terminator kit (Amersham Biosciences/GE) following the manufacturer's instructions. Each fragment was sequenced from both directions using the same primers as in the PCR reaction. Purified sequencing products were resolved using a MegaBACE 1000 instrument and MegaBACE long-read matrix (Amersham Biosciences/GE), visualized using the 
Sequence Analyzer v3.0 software (Amersham Biosciences/ GE), and assembled and analyzed using the Pregap and Gap4 software (www.cbi.pku.edu.cn/tools/staden), comparing to the sequence NT_010194, build 36 (www.ncbi. nih.gov). Sequences were verified visually by two independent readers.

Evolutionary analysis of the CYP19A1 coding sequence was performed with a likelihood ratio test using the CODEML program of the paml3.15 package (Yang 1997); the dog (Canis familiaris) XP_544678 sequence was used as the outgroup in the analysis.

\section{EMSA}

Fragments of $30 \mathrm{bp}$ in length and for each allele of the three SNPs studied were designed as probes (the sequences can be obtained on request). EMSA was performed according to standard protocols. The binding reactions were performed by pre-incubating $10 \mu \mathrm{g}$ nuclear- or total cell extracts from the neuroblastoma cell line SH-SY5Y, with $0.5 \mu \mathrm{g}$ of poly (dI-dC), $10 \mathrm{mM}$ DTT and $100 \mathrm{mM}$ $\mathrm{NaCl} .{ }^{32} \mathrm{P}$-end-labeled double-stranded probes were added, and the mixture was incubated for $20 \mathrm{~min}$ at room temperature (RT). For the supershift assays, $4 \mu \mathrm{g}$ of TFII-I or Elk-1 antibody (cat. Nos. sc-9943 X and sc-355 X; Santa Cruz Biotechnology, Inc.) were added to the reaction and incubated for another $20 \mathrm{~min}$ at RT. For the competition assays, a 100- and 200-mol excess of non-labeled oligonucleotide was added and incubated for $30 \mathrm{~min}$ at RT prior to addition of the labeled probe. The samples were electrophoresed on $5 \%$ non-denaturing polyacrylamide gels in $1 \times$ TBE (0.09 M Tris-borate, $2 \mathrm{mM}$ EDTA) at $150 \mathrm{~V}$. The radioactive pattern was visualized by autoradiography and quantified by PhosphorImager scanning (Fuji Photo Film Co., Ltd., Stamford, CT, USA). Transcription factor binding sites for both alleles of each SNP were predicted by TESS (www.cbil.upenn.edu/cgi-bin/tess/tess).

\section{Expression analysis}

Ready-made TaqMan gene expression assays for CYP19A1 (Hs00240671_m1), DYX1C1 (Hs00370049_m1), DCDC2 (Hs00393203_m1), KIAA0319 (Hs00207788_m1), ROBO1 (Hs00268049_m1), MRPL19 (Hs00608519_m1), C2ORF3 (Hs00162632_m1), and 18S rRNA (4319413E) were purchased from Applied Biosystems. We assayed expression levels for these genes in total RNA from nine different regions of adult human brain: thalamus, hypothalamus, frontal-, occipital-, parietal-, temporal cortex (cat. Nos. 6762, 6864, 6810, 6812, 6814, 6816, Ambion); hippocampus, paracentral-, postcentral gyrus (cat. Nos. 636565, 636574, 636573, Clontech); as well as from whole adult brain (cat. No. 636530, Clontech). For each tissue, three independent cDNA syntheses (500 ng total RNA per reaction) were performed using the SuperScript III firststrand synthesis kit (cat. No. 18080-051, Invitrogen). From each cDNA synthesis, quantitative real-time PCR was performed in quadruplets, using 5-50 ng of RNA per gene assay and run on ABI PRISM 7700 Sequence Detection PCR System (Applied Biosystems). All assays were performed in $10 \mu \mathrm{l}$ reactions according to the manufacturer's instructions. Relative standard expression curves were drawn for $18 \mathrm{~S}$ rRNA and all tested genes. Relative quantification of the data was performed using the comparative threshold cycle $(\mathrm{Ct})$ method (Sequence Detection System bulletin 2, Applied Biosystems) adjusting the $\mathrm{Ct}$ values to $18 \mathrm{~S}$ rRNA.

Generation of ArKO mice brain sections

ArKO mice were generated through breeding heterozygous mice (Fisher et al. 1998). ArKO +/- female mice were mated overnight with ArKO $+/-$ males and inspected at 9:00 a.m. on the following day for the presence of vaginal plug. Noon of this day was assumed to correspond to E0.5. All animals were housed in the animal-care facility with a $12 \mathrm{~h}$ light/12 h dark photo-period and given free access to tap water and rodent chow. To obtain E17.5 embryos, pregnant mice were anaesthetized deeply with $\mathrm{CO}_{2}$ and perfused with PBS followed by $4 \%$ paraformaldehyde (in 0.1 M PBS, pH 7.4). Embryos were taken out and put on ice, and brains were dissected and postfixed in the same fixative overnight at $4^{\circ} \mathrm{C}$. For the 5-month-old mice, mice were perfused individually with $\mathrm{PBS}$ followed by $4 \%$ paraformaldehyde, and brains were then removed and postfixed overnight. Sex was determined after direct visual inspection of the gonads with a dissecting microscope, and the tail and limbs were removed from each embryo for genotyping. After fixation, brains were processed for either paraffin $(6 \mu \mathrm{m})$ or frozen $(30 \mu \mathrm{m})$ sections.

Immunohistochemistry

The paraffin-embedded embryonic ArKO mice brain sections were dewaxed in xylene and rehydrated through graded alcohol to $\mathrm{H}_{2} \mathrm{O}$. Nissl staining $(0.25 \%$ thionin $)$ was used to examine the histology of embryonic brains with light microscopy. For the immunohistochemistry study, paraffin sections were processed for antigen retrieval with $10 \mathrm{mM}$ citrate buffer ( $\mathrm{pH}$ 6.0), and then processed in the same manner as the frozen sections. Briefly, sections were blocked for $30 \mathrm{~min}$ with $1 \% \mathrm{H}_{2} \mathrm{O}_{2}$ followed by $10 \%$ normal serum, rinsed three times with $\mathrm{PBS}$, and incubated overnight at $4^{\circ} \mathrm{C}$ with the following antibodies: polyclonal rabbit antiEGF (Santa Cruz Biotechnology) and mouse anti-NeuN (MAB377, Chemicon) were used at 1:100, and the 
anti-parvalbumin mouse monoclonal antibody (Swant, Switzerland) was used at 1:1,000. After washing, sections were incubated with $\mathrm{Cy} 3$-conjugated anti-rabbit or $\mathrm{Cy} 3-$ conjugated anti-mouse antibodies (Jackson ImmunoResearch) in 1:200 dilutions for $2 \mathrm{~h}$ at RT. Parvalbumin-positive cells were counted on images in an area of $200 \times 200 \mu \mathrm{m}$ in the somatosensory cortex in coronal sections (three animals per condition, 10 images each). All pictures were location-matched between WT and the ArKO mice. Statistical analysis was performed using Student's $t$ test.

\section{Neuron quantification}

Mice were anaesthetized (Pentobarbitol; $0.2 \mathrm{ml}$ i.p./20 g) and perfused through the heart via the ascending aorta with $20 \mathrm{ml} \mathrm{Ca}{ }^{2+}$-free Tyrode's buffer $\left(37^{\circ} \mathrm{C}\right)$, followed by $20 \mathrm{ml}$ of a mixture of $4 \%$ paraformaldehyde and $0.2 \%$ picric acid diluted in $0.16 \mathrm{M}$ phosphate buffer ( $\mathrm{pH} 6.9$ ) and $50 \mathrm{ml}$ of the same fixative at $4^{\circ} \mathrm{C}$ for $5 \mathrm{~min}$. Brains were removed and post-fixed in the same fixative for $90 \mathrm{~min}$ at $4^{\circ} \mathrm{C}$, and finally immersed for $48 \mathrm{~h}$ in $10 \%$ sucrose dissolved in phosphate buffered saline (PBS, pH 7.4) containing $0.01 \%$ sodium azide (Sigma, St. Louis, MO, USA) and $0.02 \%$ Bacitracin (Sigma) at $4{ }^{\circ} \mathrm{C}$, before rapid freezing by dry ice and sectioned at $20 \mu \mathrm{m}$ (cryostat; Leica CM 1850). The neuronal density of the number of NeuN immunoreactive cell bodies in the somatosensory cortex was estimated by systemic random sampling of four sections per animal (ArKO, $n=4$; WT, $n=5$ ). Images of the somatosensory cortices were scanned using an Olympus BX-51 fluorescent microscope at $\times 100$ magnification using the TRITC UV filter. A counting grid was placed over the somatosensory cortex with dimensions of each counting frame being $251.5 \times 83.2 \mu \mathrm{m}=0.02 \mathrm{~mm}^{2}$. Cells falling within each frame were quantified. For counting purposes, NeuN immunoreactive cell bodies falling on the upper and right boundaries of the counting frames were counted while NeuN immunoreactive cell bodies that fell on the lower and left boundaries of each frame were ignored.

\section{Commissural measurements}

Five two-month-old male ArKO mice and five WT littermates were used to measure the commissures. The commissures were visualized by cutting the fixed brain in half at the mid-sagittal plane, and staining the myelinated structures with gold chloride (Wahlsten et al. 2003). Digital images were obtained with Olympus SZx9 Research Stereo microscope and Olympus DP70 digital microscope camera, and the areas of $\mathrm{CC}, \mathrm{HC}$ and anterior commissure (AC) were measured with the ImageJ program (Abràmoff et al. 2004).
Process outgrowth of rat hippocampal neurons

Hippocampal neuronal cultures were prepared from the brains of E17 rat fetuses (Brewer and Cotman 1989). Briefly, the hippocampi were dissected, the meninges removed and the neurons dissociated in single-cell suspension with papain $(0.5 \mathrm{mg} / \mathrm{ml})$ digestion and mechanical trituration. The cells were centrifuged, suspended in DMEM containing Glutamax I and supplemented with $10 \%$ heat inactivated fetal bovine serum (FBS), $100 \mathrm{U} / \mathrm{ml}$ penicillin, and $100 \mu \mathrm{g} / \mathrm{ml}$ streptomycin (DMEM medium; Gibco BRL) and 100,000 cells/well on 12-well plates were plated onto glass coverslips coated with $0.5 \mathrm{mg} / \mathrm{ml}$ poly-L-ornithine (Sigma) and $10 \mathrm{mg} / \mathrm{ml}$ laminin (Invitrogen). The cells were cultured in neurobasal medium (Gibco), without phenol red supplemented with B27 (Gibco), penicillin-streptomycin (Euroclone) and L-glutamine (Euroclone) at $37^{\circ} \mathrm{C}$ in $5 \% \mathrm{CO}_{2}$. After $24 \mathrm{~h}$ in vitro, cells were treated with only solvent; or testosterone ( $20 \mathrm{nM}$, Fluka) or testosterone $(20 \mathrm{nM})$ and letrozole $(100 \mathrm{nM}$, Advanced Technology and Industrial Co., Hong Kong); or testosterone $(20 \mathrm{nM})$, letrozole $(100 \mathrm{nM})$ and $17 \beta$-estradiol $(1 \mathrm{nM}$, Sigma); or $17 \beta$-estradiol $(1 \mathrm{nM})$ only. After 3-4 days of in vitro culture, cells were fixed with $4 \%$ paraformaldehyde and immunostained with the neuronal marker TuJ1 (Covance). Confocal microscope pictures were taken (Zeiss Axioplan 2, Pascal software) and total neurite outgrowth per neuron was measured using Image-Pro Plus software tracing all processes $(N \sim 70 /$ group $)$.

Acknowledgments We wish to thank Juliana Bloom, Lisa Freebairn, Amy Hansen, Christopher Millard, Dmitry Leontiev, Carlin Miller for their assistance in data collection, Helge Neidt for sample handling, Kristina Duvefelt and Ingegerd Fransson for excellent genotyping and technical support as well as Margaret Warner for suggestions and support in the design and analysis of the ArKO mice experimental work. We also wish to express our appreciation to the speech-language pathologists who assisted us in recruiting participants and to the families who generously agreed to participate. This work was supported by the National Institutes of Health-National Institute on Deafness and Other Communication Disorders (NIHNIDCD) grants to B.A.L, NIH-NIDCD to S.I., NIH-Eunice Kennedy Shriver Institute of Child Health and Human Development (NICHD) to G.W.H., NIH-NICHD 5P50-HD027802 to R.K.O. (with B.F.P. and S.D.S.), NIH-National Center for Research Resources (NCRR) to C.M.S., Sigrid Jusélius Foundation to J.K. and E.C., Academy of Finland to J.K., H.L. and E.C., Swedish Research Council to J.K., M.N. and M.P.-J., Swedish Cancer Fund to J.-Å.G. and J.K., Hjärnfonden (Swedish Brain Foundation) to J.K. and I.T.-P., the Centennial Foundation of Helsingin Sanomat to H.A., the Päivikki and Sakari Sohlberg Foundation, the Swedish Royal Bank Tercentennial Foundation and Knut and Alice Wallenberg Foundation to J.K. This study was also supported by the European Union through the CASCADE Network of Excellence and the CRESCENDO Integrated Project; by a training grant (HL07567) from the National Heart, Lung and Blood Institute. The Colorado Learning Disabilities Research Center is also funded by NICHD (grant nr. 5P50HD027802). Some of the analyses were performed using the program package S.A.G.E. (2003 [Release 4.5]), which is supported by NIH-NCRR RR03655. 
Conflict of interest J.- $\AA$.G is consultant and shareholder of KaroBio AB.

Open Access This article is distributed under the terms of the Creative Commons Attribution License which permits any use, distribution, and reproduction in any medium, provided the original author(s) and the source are credited.

\section{References}

Abràmoff MD, Magalhães PJ, Ram SJ (2004) Image processing with ImageJ. Biophotonics Int 11(7):36-42

Andrews W, Liapi A, Plachez C, Camurri L, Zhang J, Mori S, Murakami F, Parnavelas JG, Sundaresan V, Richards LJ (2006) Robo1 regulates the development of major axon tracts and interneuron migration in the forebrain. Development 133(11): 2243-2252

Anthoni H, Zucchelli M, Matsson H, Muller-Myhsok B, Fransson I, Schumacher J, Massinen S, Onkamo P, Warnke A, Griesemann H, Hoffmann P, Nopola-Hemmi J, Lyytinen H, Schulte-Korne G, Kere J, Nothen MM, Peyrard-Janvid M (2007) A locus on 2p12 containing the co-regulated MRPL19 and C2ORF3 genes is associated to dyslexia. Hum Mol Genet 16(6):667-677

Ayer S, Benyajati C (1992) The binding site of a steroid hormone receptor-like protein within the Drosophila Adh adult enhancer is required for high levels of tissue-specific alcohol dehydrogenase expression. Mol Cell Biol 12(2):661-673

Azcoitia I, Yague JG, Garcia-Segura LM (2011) Estradiol synthesis within the human brain. Neuroscience 191:139-147

Bakker JB, Honda S, Harada N, Balthazart J (2004) Relationships between aromatase activity in the brain and gonads and behavioural deficits in homozygous and heterozygous aromatase knockout mice. J Neuroendocrinol 16(5):483-490

Barrett JC, Fry B, Maller J, Daly MJ (2005) Haploview: analysis and visualization of LD and haplotype maps. Bioinformatics 21(2): 263-265

Beyer C (1999) Estrogen and the developing mammalian brain. Anat Embryol (Berl) 199(5):379-390

Bishop DV, Snowling MJ (2004) Developmental dyslexia and specific language impairment: same or different? Psychol Bull 130(6):858-886

Boon WC, Chow JD, Simpson ER (2010) The multiple roles of estrogens and the enzyme aromatase. Prog Brain Res 181: 209-232

Brewer GJ, Cotman CW (1989) Survival and growth of hippocampal neurons in defined medium at low density: advantages of a sandwich culture technique or low oxygen. Brain Res 494(1): $65-74$

Bulun SE, Takayama K, Suzuki T, Sasano H, Yilmaz B, Sebastian S (2004) Organization of the human aromatase p450 (CYP19) gene. Semin Reprod Med 22(1):5-9

Cammarota M, Bevilaqua LR, Ardenghi P, Paratcha G, Levi de Stein M, Izquierdo I, Medina JH (2000) Learning-associated activation of nuclear MAPK, CREB and Elk-1, along with Fos production, in the rat hippocampus after a one-trial avoidance learning: abolition by NMDA receptor blockade. Brain Res Mol Brain Res 76(1):36-46

Catts HW, Fey ME, Tomblin JB, Zhang X (2002) A longitudinal investigation of reading outcomes in children with language impairments. J Speech Lang Hear Res 45(6):1142-1157

Catts HW, Adlof SM, Hogan TP, Weismer SE (2005) Are specific language impairment and dyslexia distinct disorders? J Speech Lang Hear Res 48(6):1378-1396
Chen CP, Lin SP, Tsai FJ, Chern SR, Lee CC, Wang W (2008) A 5.6$\mathrm{Mb}$ deletion in $15 \mathrm{q} 14$ in a boy with speech and language disorder, cleft palate, epilepsy, a ventricular septal defect, mental retardation and developmental delay. Eur J Med Genet 51(4): $368-372$

Chow JD, Simpson ER, Boon WC (2009) Alternative 5'-untranslated first exons of the mouse Cyp19A1 (aromatase) gene. J Steroid Biochem Mol Biol 115(3-5):115-125

Conti-Ramsden G, Hesketh A (2003) Risk markers for SLI: a study of young language-learning children. Int $\mathbf{J}$ Lang Commun Disord 38(3):251-263

DeFries JC, Filipek PA, Fulker DF, Olson RK, Pennington BF, Smith SD, Wise BW (1997) Colorado Learning Disabilities Research Center. Learn Disabil Multidiscip J 8(1):7-19

Diotel N, Le Page Y, Mouriec K, Tong SK, Pellegrini E, Vaillant C, Anglade I, Brion F, Pakdel F, Chung BC, Kah O (2010) Aromatase in the brain of teleost fish: expression, regulation and putative functions. Front Neuroendocrinol 31(2):172-192

Dollaghan C, Campbell TF (1998) Nonword repetition and child language impairment. J Speech Lang Hear Res 41(5):1136-1146

Dudbridge F (2003) Pedigree disequilibrium tests for multilocus haplotypes. Genet Epidemiol 25(2):115-121

Elston RC, Idury RM, Cardon LR, Lichter JB (1999) The study of candidate genes in drug trials: sample size considerations. Stat Med 18(6):741-751

Fisher R (1948) Combining independent tests of significance. Am Stat 2:30

Fisher CR, Graves KH, Parlow AF, Simpson ER (1998) Characterization of mice deficient in aromatase (ArKO) because of targeted disruption of the cyp19 gene. Proc Natl Acad Sci U S A 95:6965-6970

Forlano PM, Schlinger BA, Bass AH (2006) Brain aromatase: new lessons from non-mammalian model systems. Front Neuroendocrinol 27(3):247-274

Galaburda AM, Sherman GF, Rosen GD, Aboitiz F, Geschwind N (1985) Developmental dyslexia: four consecutive patients with cortical anomalies. Ann Neurol 18(2):222-233

Garcia-Segura LM (2008) Aromatase in the brain: not just for reproduction anymore. J Neuroendocrinol 20(6):705-712

Hannelius U, Lindgren CM, Melen E, Malmberg A, von Dobeln U, Kere J (2005) Phenylketonuria screening registry as a resource for population genetic studies. J Med Genet 42(10):e60

Hannula-Jouppi K, Kaminen-Ahola N, Taipale M, Eklund R, NopolaHemmi J, Kaariainen H, Kere J (2005) The axon guidance receptor gene ROBO1 is a candidate gene for developmental dyslexia. PLoS Genet 1(4):e50

Hao J, Rapp PR, Leffler AE, Leffler SR, Janssen WG, Lou W, McKay H, Roberts JA, Wearne SL, Hof PR, Morrison JH (2006) Estrogen alters spine number and morphology in prefrontal cortex of aged female rhesus monkeys. J Neurosci 26(9): 2571-2578

Jones ME, Boon WC, McInnes K, Maffei L, Carani C, Simpson ER (2007) Recognizing rare disorders: aromatase deficiency. Nat Clin Pract Endocrinol Metab 3(5):414-421

Kaminen N, Hannula-Jouppi K, Kestila M, Lahermo P, Muller K, Kaaranen M, Myllyluoma B, Voutilainen A, Lyytinen H, Nopola-Hemmi J, Kere J (2003) A genome scan for developmental dyslexia confirms linkage to chromosome 2p11 and suggests a new locus on 7q32. J Med Genet 40(5):340-345

Karolczak M, Kuppers E, Beyer C (1998) Developmental expression and regulation of aromatase- and 5alpha-reductase type I mRNA in the male and female mouse hypothalamus. J Neuroendocrinol 10(4):267-274

Kim DW, Cheriyath V, Roy AL, Cochran BH (1998) TFII-I enhances activation of the c-fos promoter through interactions with upstream elements. Mol Cell Biol 18(6):3310-3320 
Lahiri DK, Nurnberger JI Jr (1991) A rapid non-enzymatic method for the preparation of HMW DNA from blood for RFLP studies. Nucleic Acids Res 19(19):5444

Lanfranco F, Zirilli L, Baldi M, Pignatti E, Corneli G, Ghigo E, Aimaretti G, Carani C, Rochira V (2008) A novel mutation in the human aromatase gene: insights on the relationship among serum estradiol, longitudinal growth and bone mineral density in an adult man under estrogen replacement treatment. Bone 43(3):628-635

Leppanen PH, Hamalainen JA, Salminen HK, Eklund KM, Guttorm TK, Lohvansuu K, Puolakanaho A, Lyytinen H (2010) Newborn brain event-related potentials revealing atypical processing of sound frequency and the subsequent association with later literacy skills in children with familial dyslexia. Cortex 46(10):1362-1376

Martin ER, Monks SA, Warren LL, Kaplan NL (2000) A test for linkage and association in general pedigrees: the pedigree disequilibrium test. Am J Hum Genet 67(1):146-154

Martinez-Cerdeno V, Noctor SC, Kriegstein AR (2006) Estradiol stimulates progenitor cell division in the ventricular and subventricular zones of the embryonic neocortex. Eur J Neurosci 24(12):3475-3488

Matsson H, Tammimies K, Zucchelli M, Anthoni H, Onkamo P, Nopola-Hemmi J, Lyytinen H, Leppanen PH, Neuhoff N, Warnke A, Schulte-Korne G, Schumacher J, Nothen MM, Kere J, Peyrard-Janvid M (2011) SNP variations in the 7q33 region containing DGKI are associated with dyslexia in the Finnish and German populations. Behav Genet 41(1):134-140

McEwen BS, Coirini H, Westlind-Danielsson A, Frankfurt M, Gould E, Schumacher M, Woolley C (1991) Steroid hormones as mediators of neural plasticity. J Steroid Biochem Mol Biol 39(2):223-232

Meng H, Smith SD, Hager K, Held M, Liu J, Olson RK, Pennington BF, DeFries JC, Gelernter J, O'Reilly-Pol T, Somlo S, Skudlarski P, Shaywitz SE, Shaywitz BA, Marchione K, Wang Y, Paramasivam M, LoTurco JJ, Page GP, Gruen JR (2005) DCDC2 is associated with reading disability and modulates neuronal development in the brain. Proc Natl Acad Sci U S A 102(47): 17053-17058

Naftolin F, Horvath TL, Balthazart J (2001) Estrogen synthetase (aromatase) immunohistochemistry reveals concordance between avian and rodent limbic systems and hypothalami. Exp Biol Med (Maywood) 226(8):717-725

Newbury DF, Paracchini S, Scerri TS, Winchester L, Addis L, Richardson AJ, Walter J, Stein JF, Talcott JB, Monaco AP (2011) Investigation of dyslexia and SLI risk variants in readingand language-impaired subjects. Behav Genet 41(1):90-104

Nopola-Hemmi J, Taipale M, Haltia T, Lehesjoki AE, Voutilainen A, Kere J (2000) Two translocations of chromosome 15q associated with dyslexia. J Med Genet 37(10):771-775

Nopola-Hemmi J, Myllyluoma B, Haltia T, Taipale M, Ollikainen V, Ahonen T, Voutilainen A, Kere J, Widen E (2001) A dominant gene for developmental dyslexia on chromosome 3. J Med Genet 38(10):658-664

O'Connell JR, Weeks DE (1998) PedCheck: a program for identification of genotype incompatibilities in linkage analysis. Am J Hum Genet 63(1):259-266

Ogilvy S, Ferreira R, Piltz SG, Bowen JM, Gottgens B, Green AR (2007) The SCL +40 enhancer targets the midbrain together with primitive and definitive hematopoiesis and is regulated by SCL and GATA proteins. Mol Cell Biol 27(20):7206-7219

Ogura Y, Azuma M, Tsuboi Y, Kabe Y, Yamaguchi Y, Wada T, Watanabe H, Handa H (2006) TFII-I down-regulates a subset of estrogen-responsive genes through its interaction with an initiator element and estrogen receptor alpha. Genes Cells 11(4):373-381
Paracchini S, Thomas A, Castro S, Lai C, Paramasivam M, Wang Y, Keating BJ, Taylor JM, Hacking DF, Scerri T, Francks C, Richardson AJ, Wade-Martins R, Stein JF, Knight JC, Copp AJ, Loturco J, Monaco AP (2006) The chromosome 6p22 haplotype associated with dyslexia reduces the expression of KIAA0319, a novel gene involved in neuronal migration. Hum Mol Genet 15(10):1659-1666

Pennington BF (2006) From single to multiple deficit models of developmental disorders. Cognition 101(2):385-413

Peyrard-Janvid M, Anthoni H, Onkamo P, Lahermo P, Zucchelli M, Kaminen N, Hannula-Jouppi K, Nopola-Hemmi J, Voutilainen A, Lyytinen H, Kere J (2004) Fine mapping of the 2p11 dyslexia locus and exclusion of TACR1 as a candidate gene. Hum Genet 114(5):510-516

Poelmans G, Engelen JJ, Van Lent-Albrechts J, Smeets HJ, Schoenmakers E, Franke B, Buitelaar JK, Wuisman-Frerker M, Erens W, Steyaert J, Schrander-Stumpel C (2009) Identification of novel dyslexia candidate genes through the analysis of a chromosomal deletion. Am J Med Genet B 150B(1):140-147

Poelmans G, Buitelaar JK, Pauls DL, Franke B (2010) A theoretical molecular network for dyslexia: integrating available genetic findings. Mol Psychiatry 16(4):365-382

Prange-Kiel J, Rune GM (2006) Direct and indirect effects of estrogen on rat hippocampus. Neuroscience 138(3):765-772

Raitano NA, Pennington BF, Tunick RA, Boada R, Shriberg LD (2004) Pre-literacy skills of subgroups of children with speech sound disorders. J Child Psychol Psychiatry 45(4):821-835

Ramachandran B, Schlinger BA, Arnold AP, Campagnoni AT (1999) Zebra finch aromatase gene expression is regulated in the brain through an alternate promoter. Gene 240(1):209-216

Rosen GD, Bai J, Wang Y, Fiondella CG, Threlkeld SW, Loturco JJ, Galaburda AM (2007) Disruption of neuronal migration by RNAi of Dyx1c1 results in neocortical and hippocampal malformations. Cereb Cortex 17(11):2562-2572

Saldanha CJ, Duncan KA, Walters BJ (2009) Neuroprotective actions of brain aromatase. Front Neuroendocrinol 30(2):106-118

Scerri TS, Schulte-Korne G (2010) Genetics of developmental dyslexia. Eur Child Adolesc Psychiatry 19(3):179-197

Schulte-Korne G, Deimel W, Muller K, Gutenbrunner C, Remschmidt H (1996) Familial aggregation of spelling disability. J Child Psychol Psychiatry 37(7):817-822

Schulte-Korne G, Deimel W, Remschmidt H (2001) [Diagnosis of reading and spelling disorder]. Z Kinder Jugendpsychiatr Psychother 29(2):113-116

Schulte-Korne G, Ziegler A, Deimel W, Schumacher J, Plume E, Bachmann C, Kleensang A, Propping P, Nothen MM, Warnke A, Remschmidt H, Konig IR (2007) Interrelationship and familiality of dyslexia related quantitative measures. Ann Hum Genet 71(Pt 2):160-175

Schumacher J, Anthoni H, Dahdouh F, Konig IR, Hillmer AM, Kluck N, Manthey M, Plume E, Warnke A, Remschmidt H, Hulsmann J, Cichon S, Lindgren CM, Propping P, Zucchelli M, Ziegler A, Peyrard-Janvid M, Schulte-Korne G, Nothen MM, Kere J (2006) Strong genetic evidence of DCDC2 as a susceptibility gene for dyslexia. Am J Hum Genet 78(1):52-62

Schumacher J, Hoffmann P, Schmal C, Schulte-Korne G, Nothen MM (2007) Genetics of dyslexia: the evolving landscape. J Med Genet 44(5):289-297

Shriberg LD, Tomblin JB, McSweeny JL (1999) Prevalence of speech delay in 6-year-old children and comorbidity with language impairment. J Speech Lang Hear Res 42(6):1461-1481

Sidak Z (1967) Rectangular confidence regions for the means of multivariate normal distributions. J Am Stat Assoc 62(318): 626-633

Smith SD (2007) Genes, language development, and language disorders. Ment Retard Dev Disabil Res Rev 13(1):96-105 
Stein CM, Millard C, Kluge A, Miscimarra LE, Cartier KC, Freebairn LA, Hansen AJ, Shriberg LD, Taylor HG, Lewis BA, Iyengar SK (2006) Speech sound disorder influenced by a locus in $15 q 14$ region. Behav Genet 36(6):858-868

Taipale M, Kaminen N, Nopola-Hemmi J, Haltia T, Myllyluoma B, Lyytinen H, Muller K, Kaaranen M, Lindsberg PJ, HannulaJouppi K, Kere J (2003) A candidate gene for developmental dyslexia encodes a nuclear tetratricopeptide repeat domain protein dynamically regulated in brain. Proc Natl Acad Sci U S A 100(20):11553-11558

Tapia-Paez I, Tammimies K, Massinen S, Roy AL, Kere J (2008) The complex of TFII-I, PARP1, and SFPQ proteins regulates the DYX1C1 gene implicated in neuronal migration and dyslexia. FASEB J 22(8):3001-3009

Threlkeld SW, McClure MM, Bai J, Wang Y, Loturco JJ, Rosen GD, Fitch RH (2007) Developmental disruptions and behavioral impairments in rats following in utero RNAi of Dyx1c1. Brain Res Bull 71(5):508-514

Tomblin JB, Records NL, Buckwalter P, Zhang X, Smith E, O’Brien $M$ (1997) Prevalence of specific language impairment in kindergarten children. J Speech Lang Hear Res 40(6):1245-1260

Tomblin JB, Zhang X, Buckwalter P, Catts H (2000) The association of reading disability, behavioral disorders, and language impairment among second-grade children. J Child Psychol Psychiatry 41(4):473-482

Torppa M, Lyytinen P, Erskine J, Eklund K, Lyytinen H (2010) Language development, literacy skills, and predictive connections to reading in Finnish children with and without familial risk for dyslexia. J Learn Disabil 43(4):308-321

Vieland VJ (2001) The replication requirement. Nat Genet 29(3): 244-245

Wahlsten D, Colbourne F, Pleus R (2003) A robust, efficient and flexible method for staining myelinated axons in blocks of brain tissue. J Neurosci Methods 123(2):207-214

Walker AH, Najarian D, White DL, Jaffe JF, Kanetsky PA, Rebbeck TR (1999) Collection of genomic DNA by buccal swabs for polymerase chain reaction-based biomarker assays. Environ Health Perspect 107(7):517-520

Wang Y, Paramasivam M, Thomas A, Bai J, Kaminen-Ahola N, Kere J, Voskuil J, Rosen GD, Galaburda AM, Loturco JJ (2006) DYX1C1 functions in neuronal migration in developing neocortex. Neuroscience 143(2):515-522

Wise JC, Sevcik RA, Morris RD, Lovett MW, Wolf M (2007) The relationship among receptive and expressive vocabulary, listening comprehension, pre-reading skills, word identification skills, and reading comprehension by children with reading disabilities. J Speech Lang Hear Res 50(4):1093-1109

Yang Z (1997) PAML: a program package for phylogenetic analysis by maximum likelihood. Comput Appl Biosci 13(5):555-556

Ziegler A, Konig IR, Deimel W, Plume E, Nothen MM, Propping P, Kleensang A, Muller-Myhsok B, Warnke A, Remschmidt H, Schulte-Korne G (2005) Developmental dyslexia-recurrence risk estimates from a german bi-center study using the single proband sib pair design. Hum Hered 59(3):136-143 